\title{
th. 2891
}

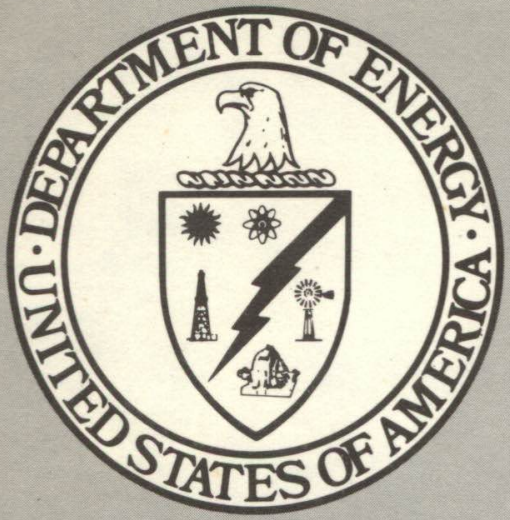

\section{MASTER}

COO-4057-8

GAS REACTOR INTERNATIONAL COOPERATIVE PROGRAM INTERIM REPORT

Construction and Operating Experience of Selected European Gas-Cooled Reactors

September 1978

Work Performed Under Contract No. EN-77-C-02-4057

General Electric Company

Advanced Reactor Systems Department

Sunnyvale, California 


\section{DISCLAIMER}

This report was prepared as an account of work sponsored by an agency of the United States Government. Neither the United States Government nor any agency Thereof, nor any of their employees, makes any warranty, express or implied, or assumes any legal liability or responsibility for the accuracy, completeness, or usefulness of any information, apparatus, product, or process disclosed, or represents that its use would not infringe privately owned rights. Reference herein to any specific commercial product, process, or service by trade name, trademark, manufacturer, or otherwise does not necessarily constitute or imply its endorsement, recommendation, or favoring by the United States Government or any agency thereof. The views and opinions of authors expressed herein do not necessarily state or reflect those of the United States Government or any agency thereof. 


\section{DISCLAIMER}

Portions of this document may be illegible in electronic image products. Images are produced from the best available original document. 


\section{NOTICE}

This report was prepared as an account of work sponsored by the United States Government. Neither the United States nor the United States Department of Energy, nor any of their employees, nor any of their contractors, subcontractors, or their employees, makes any warranty, express or implied, or assumes any legal liability or responsibility for the accuracy, completeness or usefulness of any information, apparatus, product or process disclosed, or represents that its use would not infringe privately owned rights.

This report has been reproduced directly from the best available copy.

Available from the National Technical Information Service, U. S. Department of Commerce, Springfield, Virginia 22161.

Price: Paper Copy $\$ 5.25$

Microfiche $\$ 3.00$ 


\title{
GAS REACTOR INTERNATIONAL COOPERATIVE PROGRAM INTERIM REPORT
}

\author{
CONSTRUCTION AND OPERATING EXPERIENCE \\ OF SELECTED EUROPEAN GAS-COOLED REACTORS
}

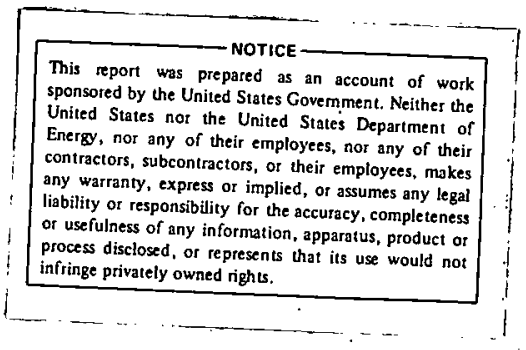

\section{For}

NUS CORPORATION

Rockville, Maryland

GENERAL ELECTRIC

\section{Prepared for}

The U.S. Department of Energy

September 1978
Contract No. EN-77-C-02-4057 


\section{ABSTRACT}

The construction and operating experience of selected European GasCooled Reactors is summarized along with technical descriptions of the plants. Included in the report are the AVR Experimental Pebble Bed Reactor, the Dragon Reactor, AGR Reactors, and the Thorium High Temperature Reactor (THTR). The study demonstrates that the European experience has been favorable and forms a good foundation for the development of Advanced High Temperature Reactors.

By agreement, this report has been revieused by the cognizant Federal. Republic of Germany industrial and laboratory operations and the resultiny commments incorponuted or noted herein. 
ABSTRACT

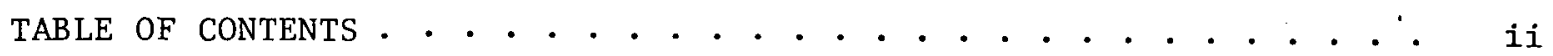

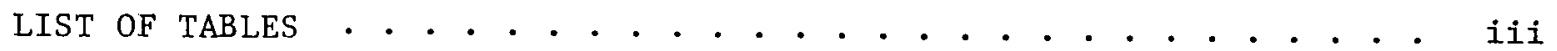

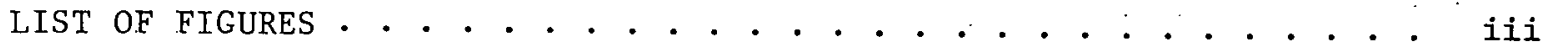

SECTION 1 - INTRODUCTION. . . . . . . . . . . . . . . . . . . . 1-2

1.1 Background . . . . . . . . . . . . . . . . . . . . . . . . . . 1-2

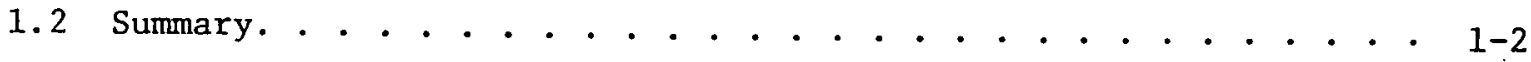

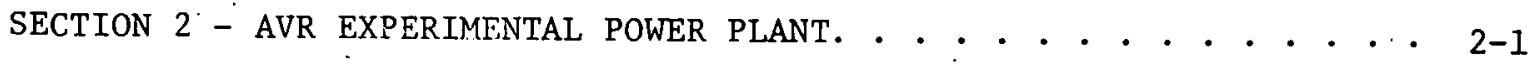

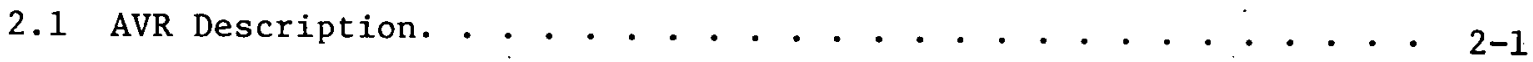

2.2 AVR Operating Experience . . . . . . . . . . . . . . . . . . . . 2-4

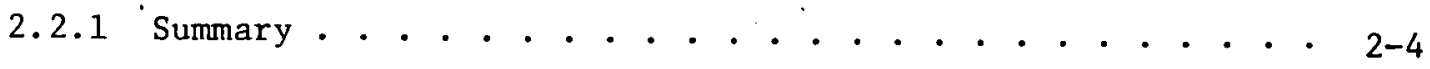

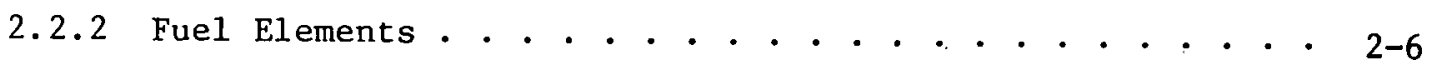

2.2 .3 Coolant Gas . . . . . . . . . . . . . . . . . . . . 2-10

2.2 .4 Reactor Components. . . . . . . . . . . . . . . . . . 2-11

2.2 .5 Health Physics. . . . . . . . . . . . . . . . . . . 2-13

2.2.6 Elevated Temperature $\left(950^{\circ} \mathrm{C}\right.$ Operation). . . . . . . . . . 2-13

SECTION 3 - DRAGON REACTOR EXPERIMENT . . . . . . . . . . . . . . . 3-1

3.1 Dragon Reactor Description . . . . . . . . . . . . . . . . . 3-1

3.2 Dragon Reactor Experience. • . . . . . . . . . . . . . . . . . . 3-4

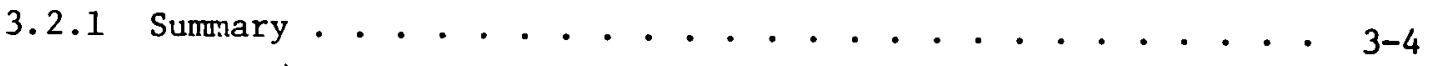

3.2.2 Core and Fuel Performance . . . . . . . . . . . . . . . 3-6

3.2 .3 Coolant Gas . . . . . . . . . . . . . . . . . . . . 3-14

3.2 .4 Reactor Components and Materials. . . . . . . . . . . . . 3-15

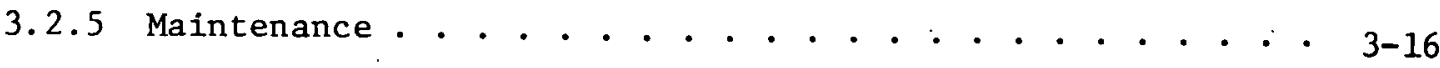

SECTION 4 - ADVANCED GAS-COOLED REACTORS (AGR). • . . • . • • • • 4-1

4.1 Circulators. . . . . . . . . . . . . . . . . . . . . . 4-1

4.2 Single- and Multi-Cavity Pressure Vessels. . . . . . . . . . . 4-2

4.3 Insulation . . . . . . . . . . . . . . . . . . . . . 4-3

SECTION 5 - THORIUM HIGH TEMPERATURE REACTOR (THTR) . . . . . . . . 5-1

5.1 Background . . . . . . . . . . . . . . . . . . . . . . 5-1

5.2 Plant Data . . . . . . . . . . . . . . . . . . . . . 5-1

5.2.1 Prestressed Concrete Reactor Vessel (PCRV). . . . . . . 5-3 
Page

5:2.2 Pebble Red Core................. 5-3

5.2.3 Fuel Handling System. . . . . . . . ... . . . 5-5

5.2 .4 Reactor Metallic Internals. . . . . . . . . . 5-5

5.2.5 Steam Generators and Circulators. . . . . . . . . 5-10

5.3 THTR Licensing Status. . . . . . . . . . . . . . . . 5-11

SECTION 6 - REFERENCES. . . . . . . . . . . . . . . . 6-1

\section{LIST OF TABLES}

Table No.

$\underline{\text { Page }}$

2-1 Fuel Elements in the AVR Circuit and Their Irradiation . . . . . . . . . . . . . . 2-8

2-2 Specific Activity of Solid Fission and Activation Products in the Hot and Cold Sections of the Primary Circuit at Different Hot Gas Temperatures . . . . . 2-10

2-3 Accumulation of Waste Water and Associated Activity from the AVR......... . . . . . . . . 2-14

2-4 Release of Radioactive Materials to the Atmosphere, AVR Experimental Nuclear Power Plant . . . . . . . . 2-14

2-5 Concentrations of Solid Fission Products in AVR at $950^{\circ} \mathrm{C}$ Operation. . . . . . . . . . . . . . 2-16

5-1 THTR Basic Design Data. . . . . . . . . . . . . 5-2

Figure No.

2-1 Vertical Cross Section of the AVR. . . . . . . . . . . 2-2

2-2 Simplified Schematic Diagram of Shutdown Rods with Drive. . . . . . . . . . . . . . . . . . 2-4

2-3 Schematic Diagram Illustrating the Principle of the Fuel Handling Equipment. . . . . . . . . . . . 2-5

2-4 Availability of Time and Work for the AVR for the Years 1968-1974. . . . . . . . . . . . . . . 2-5

2-5 Different Types of Fuel Elements in the AVR. . . . . . . . 2-7

2-6 Relative Release of Fission Noble Gases. . . . . . . . . . 2-9

2-7 $\gamma$-Dose Rate Share $(\%)$ of Released Fission Products in the AVR Reactor.................. 2-16

2-8 Activity of Released Fission Products in the AVR Reactor. . . . . . . . . .. . . . . . 2-16

2-9 Temperatures in a Vertical Cross Section Across the AVR at 850 and $950^{\circ} \mathrm{C}$ Average Hot-Gas Temperature . . . . 2-17 
2-10 Temperatures in a Horizontal Cross Section a Across the Centre of the AVR Core at $850^{\circ}$ and $950^{\circ} \mathrm{C}$ Average Hot-Gas Temperature. . . . . . . . . . . 2-17

3-1 Control Arrangement of the Dragon Core . . . . . . . 3-2

3-2 Section of Dragon Reactor Showing Coolant Flow . . . . 3-3

3-3 Section of Circulator and Heat Exchanger Unit. . . . . 3-4

3-4 General Arrangement of Dragon-Reactor Plant. . . . . 3-5

3-5 The Development of Fuel Elements for the Dragon Reactor. 3-7

3-6. Dragon Reactor-Coolant Mass Flow Transient . . . . . 3-9

3-7 Reactor Response to Fast Load Pickup from 75\% to $90 \%$ of Full Power . . . . . . . . . . . . . . 3-10

3-8 Response to a Negative Reactivity Step . . . . . . . 3-11

3-9 Variation of Xe-133 Release/Birth Ratio With Time. . . 3-12

3-10 Mechanical Endurance Diagram for Coated Particle Fuels . 3-13

5-1 THTR Prestressed Concrete Reactor Vessel . . . . . . 5-4

5-2 THTR Ceramic Reactor Internals . . . . . . . . . 5-6

5-3 THTR Fuel Handling System Flow Schematic . . . . . . 5-7

5-4 THTR Fuel Handling System Physical Arrangement . . . . 5-8

5-5 THTR Reactor Metallic Internals. . . . . . . . . 5-9 
SECTION 1

INTRODUCTION

\subsection{BACKGROUND}

As part of General Electric Company's evaluation of pebble bed gascooled reactors for the U.S. Department of Energy, previous high temperature reactor experience in Europe was reviewed. Of particular interest were the AVR Experimental Power Plant and the Thorium High Temperature Reactor (THTR), since these reactors actually utilized the pebble bed concept. The Dragon Reactor and the AGRs of the United Kingdom were also studied for applicability of data to advanced High Temperature Reactors. The following report, prepared jointly by General Electric Company and NUS Corporation, describes these selected gas-cooled reactors.

\subsection{SUMMARY}

For over twenty years several countries, such as the United States, Germany, England, France, and Switzerland, have carried out intensive development programs for the development of the gas-cooled High Temperature Reactor. The reasons for the intensive effort are the potential advantages that the High Temperature Reactor offers as a source of electric power generation and nuclear process heat. Some of these advantages are the following:

a) High nuclear fuel conversion efficiency, providing a better utilization of uranium and, in particular, thorium reserves.

b) High degree of inherent safety.

c) High efficiency electricity generation, using either the indirect steam cycle or the direct cycle with helium turbine.

d) The unique property of being capable of supplying helium at high temperatures $\left(950-1000^{\circ} \mathrm{C}\right)$. 
In the United States, Peach Bottom No. 1 operated successfully from 1967 to 1974 with an overall lifetime availability of $88 \%$ and gross plant capacity factor of $74 \%$.

In Germany, the AVR reactor reached full power in 1967. For ten years it has been the test bed for various kinds of spherical fuel elements. It has demonstrated the on-line fueling method associated with the pebble bed reactor and has operated for a significant period of time at a reactor outlet temperature of $950^{\circ} \mathrm{C}$, providing data on the effects of high temperature on materials, components, and fuel element performance.*

In England the Dragon Reactor experiment contributed in the areas of fuel element design, coated particle development, and materials and component. performance at high temperatures for its ten years of operation, during which an overall availability of $78 \%$ was achieved.

The Windscale Advanced Cooled Reactor has led the way to a number of commercial AGR reactors ( $500 \mathrm{MW}_{\mathbf{e}}$ ), three of which were brought to power in 1976 and 1977 in England. Although their lower operating temperatures limit power generation to a steam cycle mode, they should contribute experience on features shared with helium-cooled reactors, such as gas circulators, single and multicavity pressure vessels, and insulation design.

In 1971 construction began on a commercial pebble bed reactor plant, based upon the excellent AVR experience. The licensing and construction efforts for THTR form the basis for future development of the pebble bed concept for advanced systems, such as process heat plants or direct cycle helium turbine plants.

Sections 2 and 3 contain respectively descriptions of the AVR and Dragon reactors and operating experience on selected topics relevant to future development of the HTR reactors, compiled from reports and papers published on the subject during operation of the plants.

Section 4 presents some general comments on AGR experience and its relevance to future gas-cooled reactors.

* KFA noted that, averaged over 10 years. the availability of the $A V R$ has been 80\%; working availability has been $90 \%$. 
Section 5 describes the design and status of the Thorium High Temperature Reactor (THTR) currently under construction in the Federal Republic of Germany. 
SECTION 2

AVR EXPERIMENTAL, POWER PLANT

The main purpose of the AVR experimental power station is to demonstrate the feasibility of the pebble bed high temperature gas-cooled reactor and the on-line refueling principle associated with this type of reactor, and to provide the basis for further development of this reactor line to the THTR 300 . (See Section 5.) The reactor description, operating experience, and comments have been compiled from a number of papers published on the subject. (Refer to References 1-9 listed in Section 6.)

\subsection{AVR DESCRIPTION}

The AVR Power Station has a helium-cooled high temperature reactor with spherical fuel elements. The pebble bed core, which measures $3 \mathrm{~m}$ in diameter and $2.5 \mathrm{~m}$ in height, contains approximately 89,000 fuel elements and 5,000 graphite spheres. It is surrounded by a graphite reflector and an outer wall made of carbon bricks. The top reflector (500 mick) and two layers of carbon ( $500 \mathrm{~mm}$ thick each) provide the shield between the core and the steam generator which is located directly above the core. Four symmetrically arranged reflector noses protrude radially into the core volume. They accommodate the guide channels for the four shutdown rods. A vertical cross section of the AVR is shown in Figure 2-1.

The helium is circulated through the core and the steam generator by means of two blowers located in the lower part of the reactor vesse1. Hot helium leaving the core passes through staggered radial slits in the top reflector and the carbon layers, and enters the stean generator via a hot-gas ceramic duct. After the steam generator, the cooler helium flows into an annular gap on the inner reactor vessel cooling the thermal shield and reactor sleeve. 


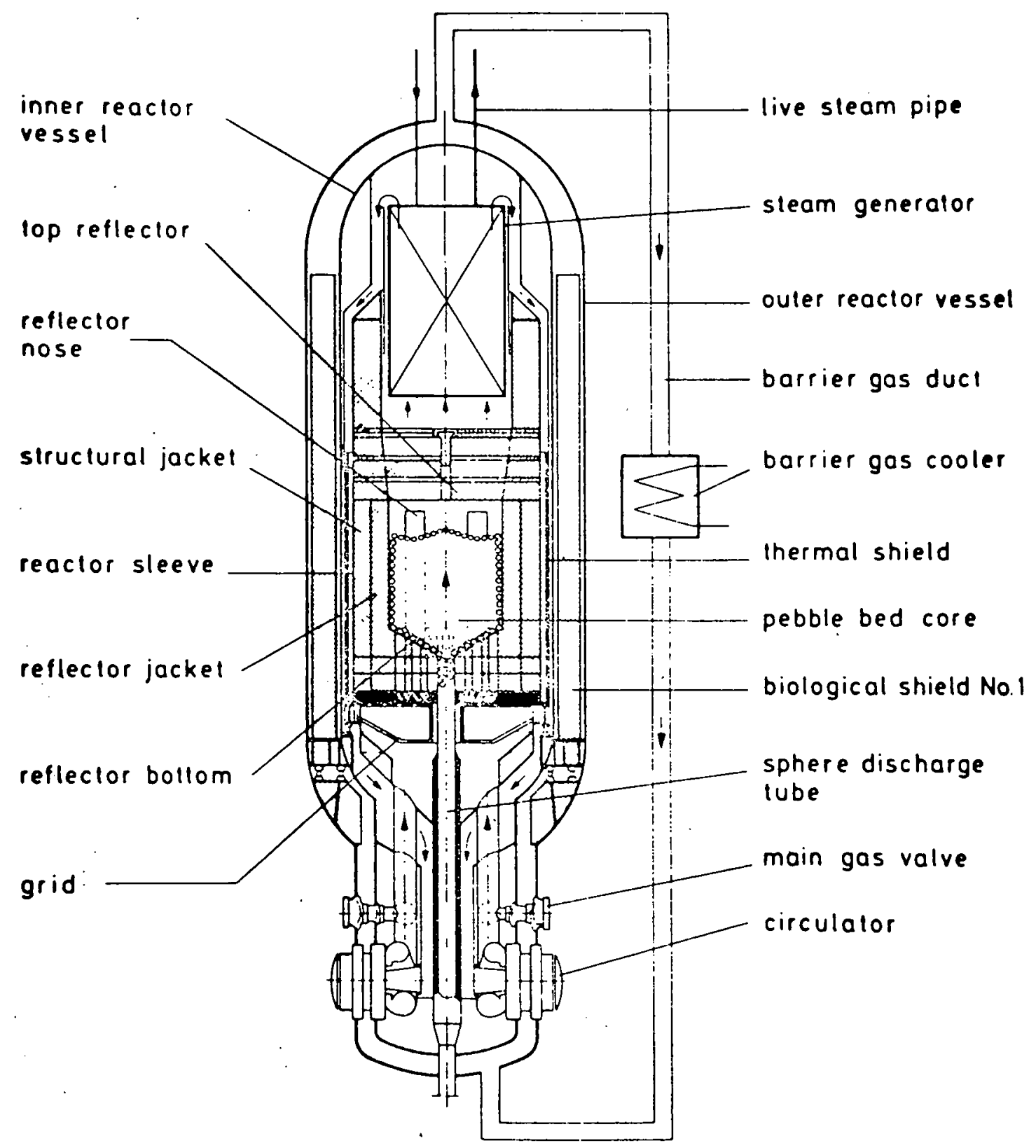

Figure 2-1. Vertical Cross Section of the AVR 
The reactor pressure vessel is doubly contained. The primary vessel and all connecting ducts are contained in a leak-tight outer vessel. In the clearance between the two vessels, pure helium is maintained at a pressure slightly higher than that of the helium in the primary circuit. The first biological shielding is also found between the two vessels, consisting of limonite and magnetite. A concrete tower with a wall $1.5 \mathrm{~m}$ thick surrounds the containment and serves as the reactor building and the outer biological shield.

The steam generator consists of four parallel once-through systems. Each system consists of parallel pipes which are individually led through the roof of the reactor vessel so that, in the event of a defect, the defective pipe can be sealed off by welding from the outside. An advantageous use of space and thermal output is obtained by using horizontal layers in the form of involutes for each separate bundle of tubes. The steam produced in the steam generator is led to a steam turbogenerator of conventional construction.

The shutdown rods are connected by a pinion to heavy counter rods and are driven into the borings of the reflector noses from below, or fall into place under the gravitational influence of counter rods when the coupling between the pinion and the drive is open. The shutdown rods have the tasks of compensating for the difference in reactivity between the hot and cold critical states and of maintaining the reactor $0.5 \%$ subcritical in the cold shutdown state. Power control is accomplished by variation of blower speed. A schematic diagram of the shutdown rods system is shown in Figure 2-2.

On-line refueling is accomplished by the fuel handling system which consists of three main parts: the circulation line, the discharge line, and the charge line. The circulation line receives fuel elements at the bottom of the core in batches, then dispatches the elements one by one to a damaged sphere separator for broken element rejection, and a burnup measuŕement device discriminates between the spheres in terms of content and burnup so that they can be returned to the core at the top through five spatially arranged positions. The , discharge line transfers the nonrecyclable elements in batches for discharge into containers. It also includes remote welding, inspection, and transporting facilities: Gravity is utilized for downward motion of the spherical elements and pneumatic energy is used for the upward motion. The charge line provides 

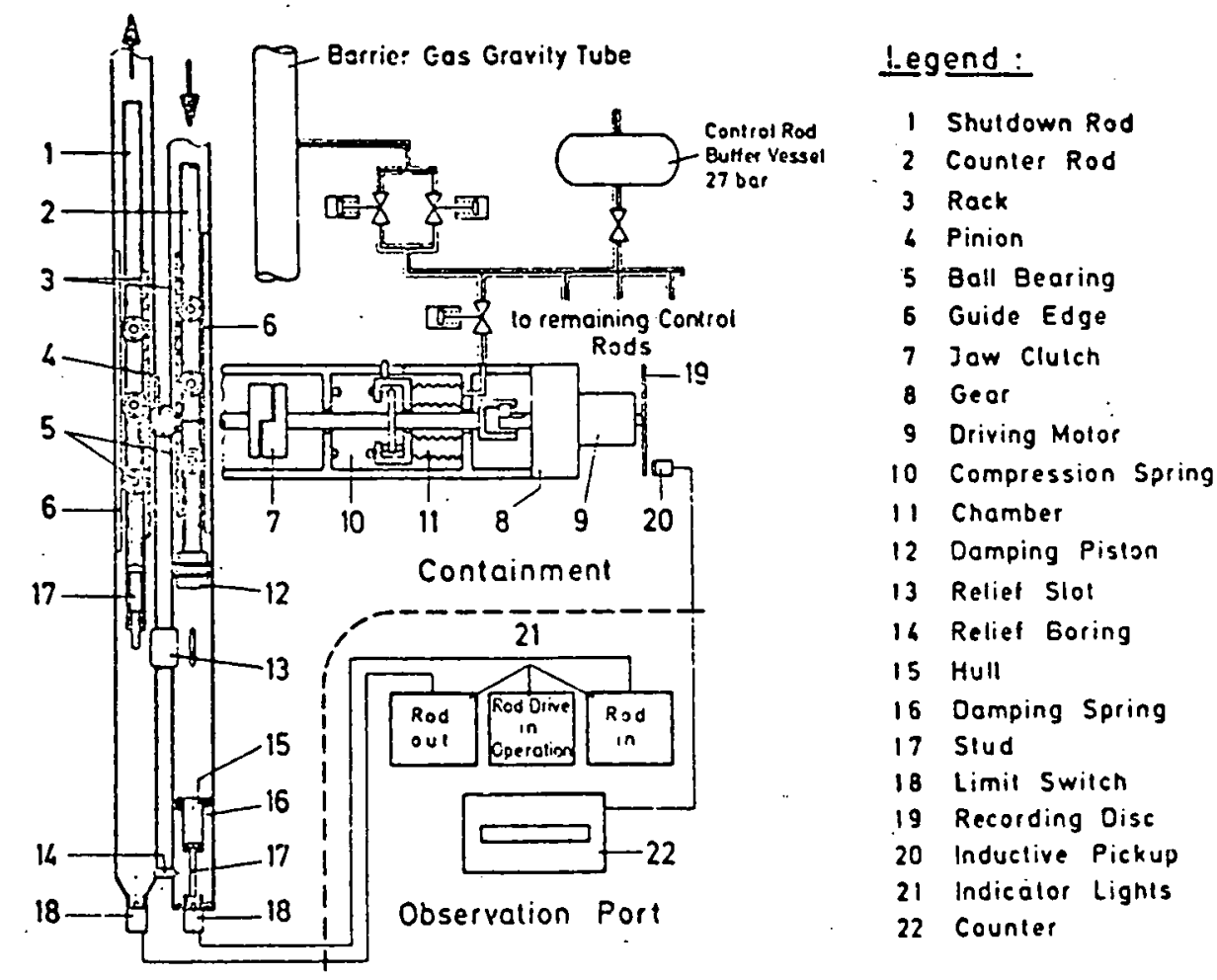

Figure 2-2. Simplified Schematic Diagram of Shutdown Rods with Drive storage and transfer of new elements in batches into the circulating line. A schematic diagram illustrating the principle of the fuel handling system is shown in Figure 2-3.

\subsection{AVR OPERATING EXPERIENCE}

\subsubsection{SUMMARY}

Power generation of the $46 \mathrm{MW}$ th reactor started in December 1967 . Experience during 10 years of operation, 1967 - 1977, showed that the plant can be operated with a high level of availability. Figure 2-4 shows operations and load factors for the plant.

The principal components of the reactor, such as the core, the shutdown rods, the blowers, and the steam generator, have been running without breakdown. Problems have been encountered with the components of the fuel handling system, the compressors used to pump the helium through the gas purification plant, and thermocouples in the hot-gas region when the average hot-gas temperature at the outlet of the core was increased from $850^{\circ}$ to $950^{\circ} \mathrm{C}$. 


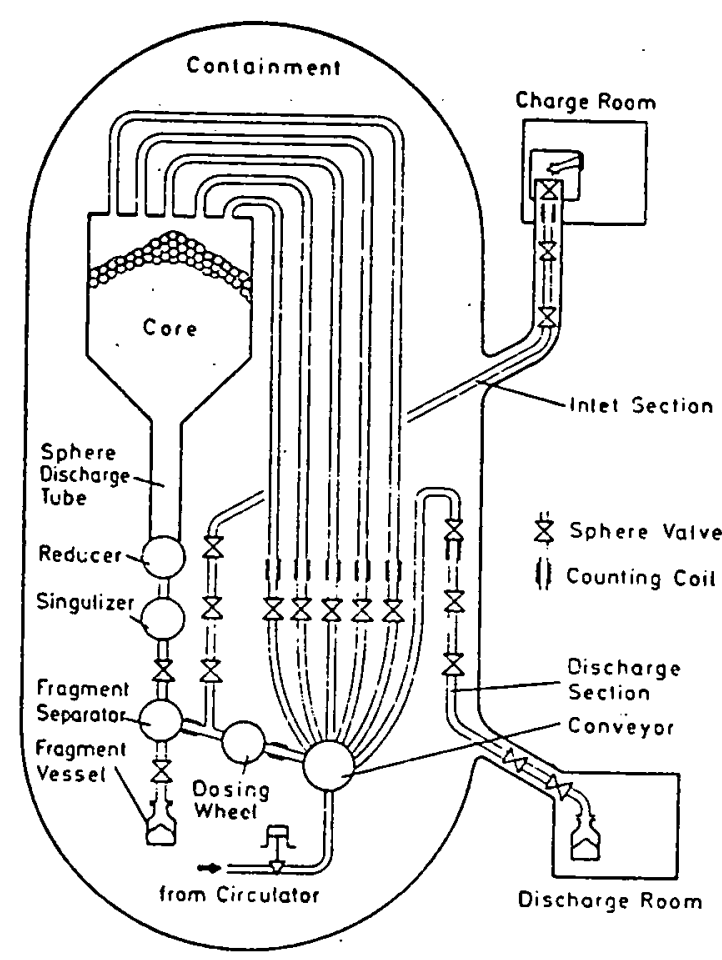

Figure 2-3. Schematic Diagram Illustrating the Principle of the Fuel Handling Equipment

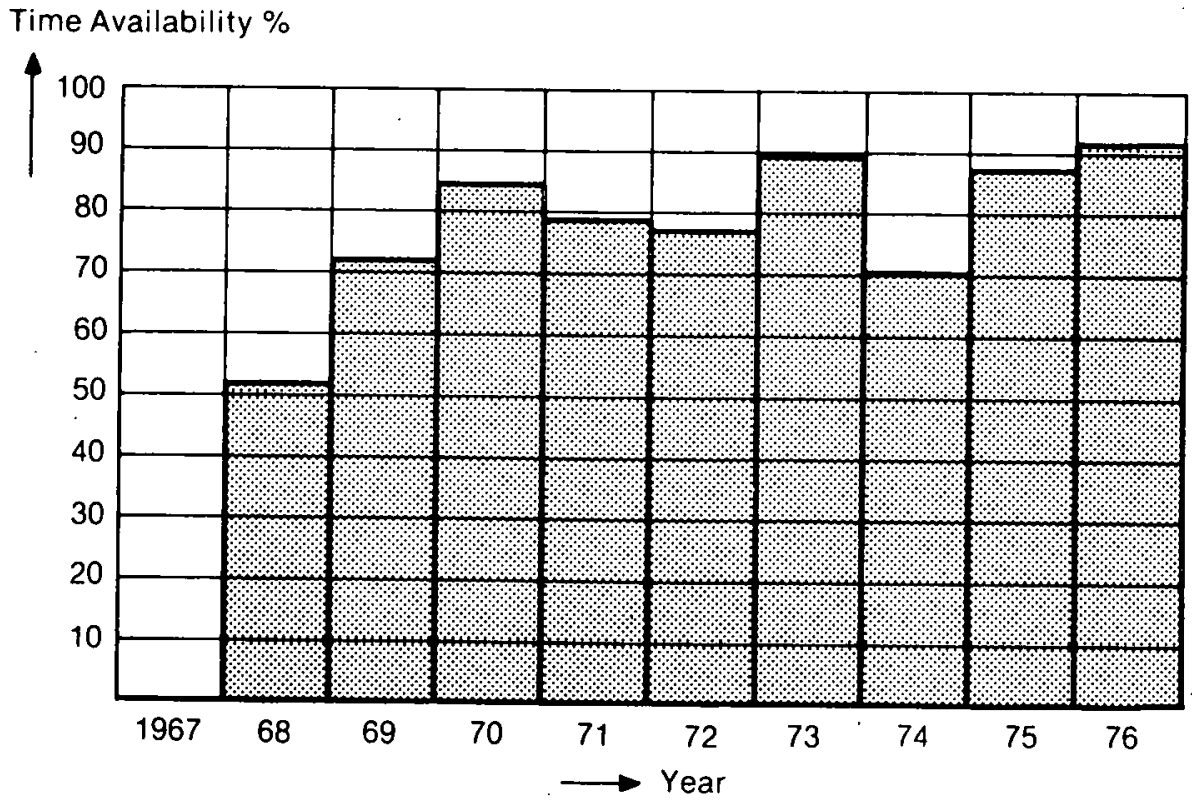

Figure 2-4. Availability of the Time and Work for the AVR for the Years 1968 1976 
The retention of gaseous fission products in the fuel has been better than expected. As a matter of fact, an unusual case has been observed in that the fuel elements are better able to retain the fission noble gases after three years of operation than at the beginning of their use, although a high heavymetal burnup is attained. The concentrations of solid fission and activation products have been low and do not imply any safety risks in loss of coolant accidents. They may present problems, however, in maintenance due to longterm plate-out on components such as the direct cycle turbine on future HTRs. The isotopes generating the most intense radiation in the AVR are Ag-110m, Cs-137, $\mathrm{Cs}-134$, and $\mathrm{Zn}-65$.

Impurities in the coolant gas were found to have no harmful effect on the components of the primary circuit. Considerable activation of the piping material at the lower part of the steam generator has occurred due to its location directly above the core.

Operation at an average hot-gas temperature of $950^{\circ} \mathrm{C}$ has shown no negative experience with the exception of thermocouple breakdown. The time period at elevated temperatures is still too short to make any conclusive statements about the influence of the high hot-gas temperature on the operation of the plant.

\subsubsection{FUEL ELEMENTS}

Three types of fuel elements have been used in the AVR core: the first charge element of U.S. origin, the so-called wallpaper-type element, and the isostatically pressed element. The elements are shown in Figure 2-5. In the case. of the first charge element, the pyrocarbon-coated fuel particles were mixed with graphite powder and inserted into a hollow graphite sphere. In the wallpaper-type element, the fuel particles are arranged on the inner surface of the hollow sphere, the interior being filled with a fuel-free graphite matrix. In the case of the pressed element, the fuel elements are pressed with graphite and binder to form a matrix surrounded by an additional fuelfree graphite zone of the same basic material. The heavy metal charge per fuel element amounts generally to $1 \mathrm{~g}$ of $\mathrm{U}-235$ of $93 \%$ enrichment, and $5 \mathrm{~g}$ or $10 \mathrm{~g}$ thorium. At the beginning, the heavy metal was charged in carbide form, but since 1972 only oxide-fueled pressed elements have been charged to the reactor. Several test charges with specific characteristics are also undergoing tests in the 

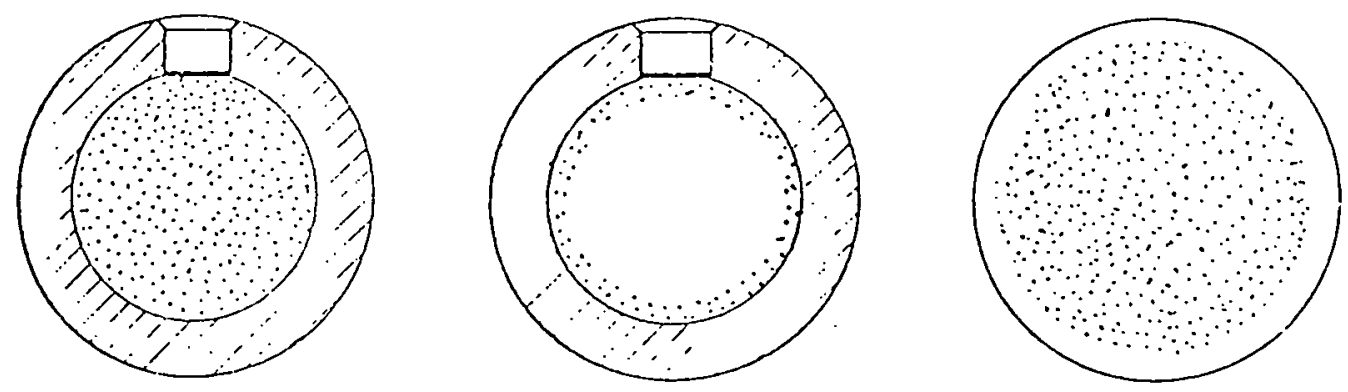

\section{First Charge Element Wallpaper Type Element Pressed Element}

Figure 2-5. Different Types of Fuel Elements in the AVR

AVR Reactor. Their characteristics are low enriched uranium, $600 \mu \mathrm{m}$ particles and high heavy metal content; elements with uranium and thorium in separate particles; and elements taken from industrial production for the first charge of the THTR-300. Table 2-1 gives a survey of the fuel elements in the circuit and the irradiation data obtained.

The fact that the pebble bed is continuously recycled and the fuel elements remain in the hottest zone of the core for a relatively short period of time has been shown to be a great advantage. The possible graphite corrosion is evenly distributed over many fuel elements and oxidation has not been the cause of any changes or defects among fuel elements examined. Visual observation shows no difference between irradiated and nonirradiated fuel elements in the fuel handling system. Metalographic examination of the outer graphite shell has shown no change. A porosity was observed in the graphite matrix inside the fuel element which is due to radiation effect of fast neutrons. It was observed that a thin layer tends to peel off the pressed fuel elements. This effect depends on the rate of corrosion attained. In the pressed fuel elements the carbide and oxide particles of the U/Th have shown good irradiation results. Particle failures have been observed on the $\mathrm{UO}_{2}$ particles in the test charge of low enriched fuel at a peak temperature greater than $1200^{\circ} \mathrm{C}$.

During reactor operations the observation has been made that the total activity of the primary circuit has decreased steadily since the start of power production. At the end of 1970 the coolant activity was approximately one quarter of the initial activity. Because of the low-level activity in the coolant and the fact that the activity very rapidly follows power and temperature changes, it is assumed that the source of the activity is not diffusion 
TABLE 2-1

FUEL ELEMENTS IN THE CIRCUIT AND THEIR IRRADIATION

(data from April 1975)***

FUEL ELEMENT

First charge element

Wallpaper-type

Pressed carbide H.M.*

Pressed oxide H.M.

Pressed oxide H.M.

\author{
$\mathrm{U}-235$ \\ Enrichment Content
}

$93 \%$

$\operatorname{l.og}$

$93 \%$

1. Og

$1.0 \mathrm{~g}$

938

1.09

$15 \%$

$1.4 \mathrm{~g}$

938

$1.0 \mathrm{~g}$

$93 \%$

$0.96 \mathrm{~g}$
MAXIMUM
fima $\star \star \%$

18.7

17.5

17.2

12.5

6.9

23.4

1.7
BURNUP

$M W d / t \quad(U+T h)$

184,000

177,000

176,000

146,000

72,000

68,000

59,000
MAXIMUM FAST 2 neute dose $\mathrm{n} / \mathrm{cm}^{2}$

$$
\begin{aligned}
& 4.3 \times 10^{21} \\
& 3.7 \times 10^{21} \\
& 4.1 \times 10^{21} \\
& 2.5 \times 10^{21} \\
& 1.4 \times 10^{21}
\end{aligned}
$$

$1.2 \times 10^{21}$

$1.1 \times 10^{21}$

${ }^{\star}$ H.M. = heavy metal

**fima $=$ fissions per initial fissionable atoms. $* * *$ Updated with FRG input of Feb. 1978 
of noble gases through the fuel particle coatings but uranium contamination of the fresh fuel during manufacture. The decrease in coolant activity, however, over the first few years of operation cannot be explained by a reduction of contamination which remained more or less the same.

A possible explanation is that neutron irradiation affects the graphite of the fuel elements in two ways, both contributing to the hindrance of diffusion out of the matrix. One is the increase in dislocation concentration in the graphite crystallites, and the other is the partial closing of micropores (detected by electron microscopic pictures). Thus, due to the longer migration period, more radioactive fission products can decay and less fission noble gases emerge into the primary circuit. It follows also that this diffusion reduction has a greater effect on short-lived isotopes than longer-lived ones. Tabulations of release-to-birth ratios (R/B) from actual measurements of isotopic activities in the coolant for various krypton and xenon isotopes strongly support this explanation of the phenomenon. Figure 2-6 shows the relative release of fission noble gases in the AVR.

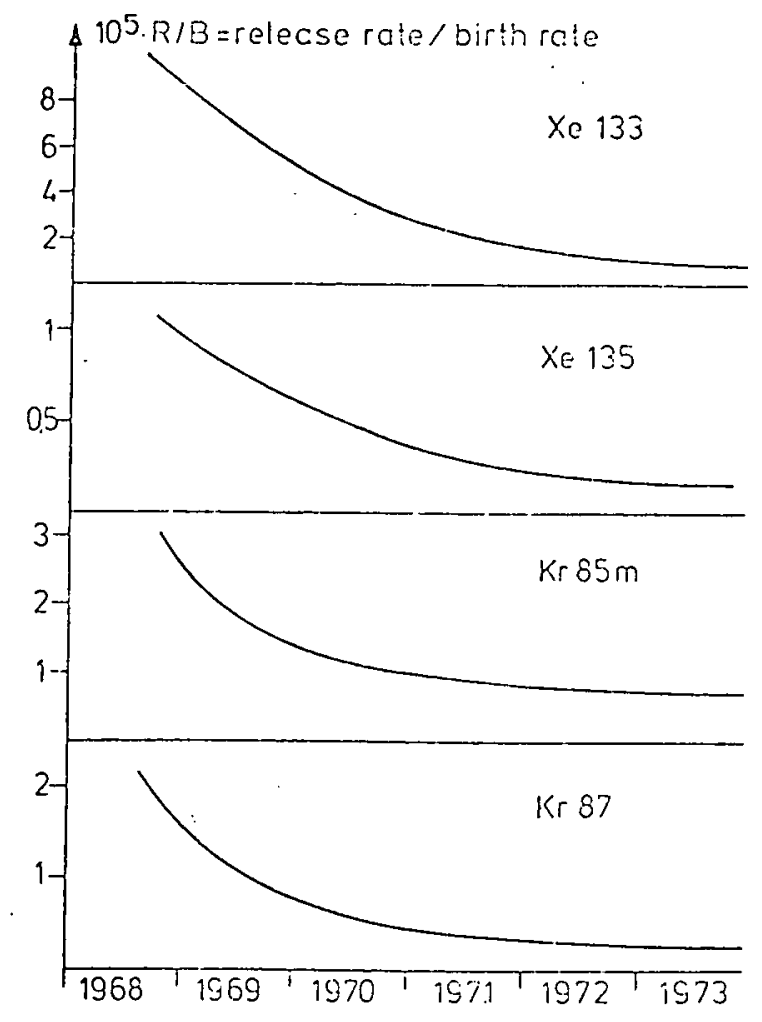

Figure 2-6. Relative Release of Fission Noble Gases 
Tests were run to determine the behavior of. solid fission products in the AVR plant. At the end of 1972, the "VAMPYR". loop. was put into operation. It is an installation for measuring the activities of solid fission and activation products in the hot gas above the top reflector in the AVR. At the same time a dust filter which determines the dust concentration and the activity on the dust was operated in the cold section of the primary circuit. The measured specific activities of various isotopes are shown in Table 2-2. The concentrations are low enough to be irrelevant in cases of accident (loss of coolant to the environment).

TABLE 2-2

SPECIFIC ACTIVITY OF SOLID FISSION AND ACTIVATION PRODUCTS IN THE HOT AND COLD SECTIONS OF THE PRIMARY CIRCUIT AT DIFFERENT HOT-GAS TEMPERATURES E

\begin{tabular}{|c|c|c|c|c|}
\hline & Spec. act & $3^{\text {hot gas }}$ & Spec. act & in $\operatorname{lid} \mathrm{M}^{3}$ gas \\
\hline SOTOP. & $\bar{E}=770^{\circ} \mathrm{C}$ & $\bar{t}=850^{\circ} \mathrm{C}$ & $\overline{\mathrm{E}}=770^{\circ} \mathrm{C}$ & $\bar{E}=850^{\circ}$ \\
\hline
\end{tabular}

$\begin{array}{llcll}\text { SR } 90 & 0.027 & 0.021 & & \\ \text { I } 131 & 2.9 & 7.6 & 0.015 & 0.12 \\ \text { CS } 134 & 0.20 & 0.22 & 0.22 & 0.081 \\ \text { CS } 137 & 0.81 & 0.38 & 0.10 & 0.025 \\ \text { Ag } 110 \mathrm{M} & 0.76 & 2.8 & 0.71 & 0.28 \\ \text { Ag } 111 & 0.08 & 51.7 & 0.00 & 8.1 \\ \text { Fe } 59 & 0.56 & 0.35 & 0.50 & 0.20 \\ \text { Cr } 51 & 0.77 & 0.35 & 0.47 & 0.10 \\ \text { Zn } 65 & 17.2 & 78.0 & 0.95 & 4.0\end{array}$

The release and plate-out rates of some of the solid fission and activation products is important not so much for safety reasons but for maintenance requirements of components in the hot section of the primary circuit. Measurements carried out in the AVR Reactor and interpretation of the results appear in Subsection 2.2.6.

\subsubsection{COOLANT GAS}

During the initial months of power production, considerable amounts of impurities were found in the helium. The causes were attributed to high water 
and $\mathrm{CO}_{2}$ content of the carbon brick with which the core is lined, and defects in diaphragm compressors of the gas purification plant allowing water inleakage. The amounts of impurities have decreased since the start of operation, but they have been considerably. higher than in the Dragon or the Peach Bottom reactors (see Subsection 3.2.3). In January 1971, the following impurities and amounts were reported:

$\begin{array}{lc}\mathrm{CO}_{2} & 5-15 \mathrm{vpm} \\ \mathrm{CO} & 20-50 \mathrm{vpm} \\ \mathrm{H}_{2} \mathrm{O} & <0.1 \mathrm{vpm} \\ \mathrm{H}_{2} & 5-15 \mathrm{vpm} \\ \mathrm{CH}_{4} & <0.2-1 \mathrm{vpm} \\ \mathrm{N}_{2} & <0.5-5 \mathrm{vpm}\end{array}$

The $\mathrm{CO}$ and $\mathrm{CO}_{2}$ content of helium probably originates from the carbon brick surrounding the core. Hydrogen most likely is the result of diffusion from the feedwater circuit through the tube walls of the steam generator. Methane probably is due to the reaction of $\mathrm{H}_{2}$ with graphite. In view of the above concentrations, it will be interesting to know whether or not any carbonization has. taken place on the heat exchanger. It was with this danger in mind that the AVR heat exchanger was constructed not of austenitic steels but of low-alloy ferritic steels. The heat exchanger, however, will not be accessible until decommissioning.

The experienced helium losses from the gas circuit are a moderate one load per annum.

\subsubsection{REACTOR COMPONENTS}

The most sensitive components were found to be two of the diaphragm compressors used to pump helium through the gas purification plant at the beginning of operation. Inleakage of water was the result of defects in these components. They were replaced with dry-operating piston compressors with excellent results in terms of performance.

Excellent performance has also been shown by the two helium blowers. It was reported in 1974 that no breakdowns had occurred because of these units and, furthermore, they had not required any servicing. The problem-free operation of the blowers is attributed to a very conventional design and careful 
mounting. It is expected that the blowers will continue to work without servicing up to the end of operation of the plant.

The steam generator is also reported to be running without breakdowns. The uninterrupted operation of the steam generator is attributed to (a) the involuted profile in the layout of the individual pipes which distributes the hot gas stream evenly, (b) soft suspension, and (c) a very thorough quality control and testing. The layers of the steam generator exposed to the gas consist of normal ferritic steels, common in the conventional boiler-type construction. They are cooled so well by the water or steam flow inside the piping that, according to the manufacturers, they can be operated at hot gas temperatures up to $1200^{\circ} \mathrm{C}$.

The location of the steam generator over the core has both advantages and disadvantages. On the plus side, the hot gas space is kept small and uncomplicated. The ceramic insulation permits operation at high gas exit temperatures which reach $1040^{\circ} \mathrm{C}$ at maximum points. These temperatures present no danger to the graphite or the carbon parts. On the minus side, the thermal neutron flux in the lower part of the steam generator is relatively high $\left(\sim 10^{10} \mathrm{n} / \mathrm{m}^{2}-\mathrm{sec}\right)$. The result is a considerable activation of the piping material and the magnetite layer on the inside of the piping. Activity on valves on the steam loop was much higher than expected and required backfitting in terms of radiation safety measures in the turbine building. Also, the low " thermal conductivity of the carbon bricks limits large rates of change of temperatures and consequently the startup and shutdown speeds of the plant.

The concern over the shutdown rods is the possibility of jamming due to the frictional forces of the rod drive assembly in the dry helium atmosphere. At the start of operations the original sliding mechanism was replaced by ball bearings coated with molybdenum disulphide. Although the rods have since operated without incident, periodic checkings of the fall and drive-in times for the shutdown rods are carried out to foresee and prevent a possible jamming.

If there is one system in the AVR plant where performance has not been satisfactory, it is the fuel handling system. It has been the system which has been subject to by far the greatest number of breakdowns. Most of the difficulties have been of a mechanical nature. The varying friction forces, either 
between the graphite fuel sphere and the steel surfaces of the equipment or the contact surfaces of the components themselves, have led to numerous blockages and jammings. Normal lubricants such as grease or oil cannot be employed for components that come into contact with the coolant gas. Some improvement has been shown with moly-coating of slide or ball bearings. The electronic counting system employed to differentiate burnup characteristics of the fuel elements was also not functioning properly due to the varying electrical conductivity of the graphite under neutron irradiation. Finally, human error in the operating mode of the system, which is not fully automatic, was another contributing factor in the system's somewhat less than satisfactory performance.*

\subsubsection{HEALTH PHYSICS}

The ability of the coated particles to hold back solid fission products is essentially the reason that experience in the area of health physics has been, on the whole, quite good. With regard to liquid effluents, Table 2-3 shows in tabular form the accumulation of water and the associated $\beta$-activity levels, with and without ${ }^{3} \mathrm{H}$ activities, for the various sources. It can be seen that the steam loop provides over $90 \%$ of the mass and over $97 \%$ of the activity content. The reduction in the activity of the liquid effluent could be reduced drastically if the steam generator was in a lower neutron flux area. Gaseous effluent activity release is shown Table 2-4. A modification in the purification system limited the release of noble gases in 1974 to about $10 \mathrm{Ci}$. Total tritium release in the same year was about $20 \mathrm{Ci}$.

\subsubsection{ELEVATED TEMPERATURE $\left(950^{\circ} \mathrm{C}\right.$ Operation)}

In February 1974, the average hot-gas temperature at the outlet of the core was increased from its original design value of $850^{\circ} \mathrm{C}$ to $950^{\circ} \mathrm{C}$. The increase in outlet temperature was intended to demonstrate that it is possible to operate a high temperature reactor for a relatively long period of time at this temperature level. It is too soon to draw any conclusions. However, some preliminary observations have been made, for example, the $70 \%$ to $90 \%$ avallabil-

"KFA noted that future plants charged by OTTO loudiny "ill no lonyer require comtinuous burn-up measurements and no resycling of partiully burnt fuel elements. In additim. difficulties with the fuel element exit tube will be avoided by the dimension of $500 \mathrm{~mm}$ being increased to $800 \mathrm{~mm}$ in the future. 
TABLE 2-3

ACCUMULATION OF WASTE WATER AND ASSOCIATED ACTIVITY FROM THE AVR

\begin{tabular}{|c|c|c|c|c|c|c|c|c|c|}
\hline Origin & & \multicolumn{8}{|c|}{\begin{tabular}{c}
\multicolumn{2}{c}{ Year } \\
$1971 \mid 1972$
\end{tabular}} \\
\hline Shower Kalet & \multirow{7}{*}{ 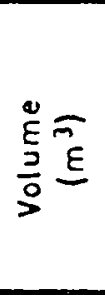 } & 73 & 129 & 619 & 250 & 665 & 297 & 626 & 2057 \\
\hline Sump Woter & & 197 & 172 & 206 & 319 & 333 & 364 & 300 & 1961 \\
\hline Cooling Loops & & 20 & 50 & 71 & 57 & 35 & 29.6 & 19 & 291.6 \\
\hline Loboralory Walee & & 1 & 2 & 1.5 & 3 & 3 & 3.8 & 3 & 17.3 \\
\hline Gos Purificalion & & 0.07 & 0.55 & - & - & - & 0.01 & 二 & 0.63 \\
\hline Sleam loop & & 10180 & 11390 & 11250 & 12950 & 3770 & 10203 & 10591 & 75336 \\
\hline Sum & & 10461 & 11764 & 11948 & 13559 & 9006 & 10897 & 111617 & 79062 \\
\hline Shower Waler & & 0.01 & 0.01 & 010 & 0.11 & 1.26 & 0.10 & $1 . !$ & 2.7 \\
\hline Sump Water & & 0.79 & 0.08 & 0.08 & 3.21 & 2.51 & Q.82 & 0.9 & 8.39 \\
\hline Cooling Loops & & 0 & 1.39 & 0.09 & $20<$ & 0.60 & 0.66 & 0.3 & 2.18 \\
\hline Laboralory Woler & & 0.02 & 0.02 & 0.01 & 0.02 & 0 & 0 & 0 & 0.07 \\
\hline Gos Purificalion & 15 & 0.01 & 0.03 & - & $=$ & - & 0 & 0 & 0.06 \\
\hline Sleam LOOD & & 1.97 & 119 & 32.6 & 216 & 556 & 596.11 & 265 & 1917.5 \\
\hline Sum & & 2.50 & 120.53 & 32.58 & 29.301 & 690.37 & 597,09 & 267.3 & 1930.2 \\
\hline Shower Water & & 0.02 & 6.68 & $0.0 \div 1$ & 0.06 & 0.07 & 0.17 & 0.05 & 6.9 \\
\hline Sump Woler & & 0.66 & 0.85 & 0.29 & 1.26 & 1.59 & 1.69 & 1.8 & 7.9 \\
\hline Cooling Loops & & 0 & 20.82 & 1.01 & 1.57 & 1.20 & 0.07 & 0.6 & 25.3 \\
\hline Laboratory Waler & 40 & 0 & 4.81 & 0.01 & 0 & 0 & 0 & 0.1 & 6.95 \\
\hline Gos Purificalion & & 0.69 & 39.61 & - & - & - & 26.0 & 3 & 63.9 \\
\hline sleam Loop & $\underline{m}$ & 12.15 & 30.03 & 39.48 & 63.62 & 40.36 & 48.43 & 76.4 & 288.45 \\
\hline Sum & & 13.12 & 102.4 & 40.87 & 46.50 & 43.19 & 74.36 & 76.56 & 397.4 \\
\hline
\end{tabular}

TABLE 2-4

RELEASE OF RADIOACTIVE MATERIALS TO THE ATMOSPHERE AVR EXPERIMENTAL NUCLEAR POWER PLANT

\begin{tabular}{|c|c|c|c|c|c|c|c|}
\hline Year & 1968 & 1969 & 1970 & 1971 & 1972 & 1973 & 1974 \\
\hline mCi Aerosols & 157 & 175 & 135 & 151. & 210 & 162 & 134 \\
\hline mCi Noble Gases & 15700 & 17484 & 30300 & 26844 & 29506 & 24401 & 10100 \\
\hline $\begin{array}{l}\text { mCi } \mathrm{H}_{3} \text { from Gas } \\
\text { Purification }\end{array}$ & $\begin{array}{l}\text { not } \\
\text { measured }\end{array}$ & $\begin{array}{c}\text { not } \\
\text { measured }\end{array}$ & $\begin{array}{c}\text { not } \\
\text { measured }\end{array}$ & $\begin{array}{c}\text { not } \\
\text { measured }\end{array}$ & not" & $\begin{array}{c}\text { not } \\
\text { measured }\end{array}$ & 2600 \\
\hline $\begin{array}{l}\text { mCi H3 from } \\
\text { Steam LoOp }\end{array}$ & $\begin{array}{c}\text { nol } \\
\text { meosured }\end{array}$ & $\begin{array}{c}\text { not } \\
\text { measured }\end{array}$ & $\begin{array}{c}\text { nol } \\
\text { measured }\end{array}$ & measured & $\begin{array}{c}\text { nol } \\
\text { measured }\end{array}$ & $\begin{array}{c}\text { not } \\
\text { meesuled }\end{array}$ & 19500 \\
\hline
\end{tabular}


ity of the power station achieved before the temperature increase was not affected.

The concentrations of $\mathrm{H}_{2}$ and $\mathrm{CO}$ in the cooling gas grew substantially at the higher temperature operations. While other impurity concentrations grew slightly or remained the same. During temperature transition periods, temporary levels of double or even treble values were reached before equilibrium was established.

The fuel elements showed no difference either in terms of corrosion or increased damage rate. The maximum central temperature of the fuel elements did not exceed $1175^{\circ} \mathrm{C}$.

The coolant gas activity did not increase. It remained constant for approximately a year and then increased continuously to $8 \times 10^{-8}$ $\mathrm{Ci} / \mathrm{cm}^{3}$. This latter increase is not attributed directly to the temperature increase, but rather to a fuel element test charge with low-enriched uranium. Some coated particles in these test fuel elements were damaged. The activity was reduced to $3 \times 10^{-8} \mathrm{Ci} / \mathrm{cm}^{3}$ after removal of some of the defective elements.

The release of solid fission products is more temperature dependent than for noble gases. Measurements of concentrations in the hot and cold sections of the primary circuit at $950^{\circ} \mathrm{C}$ operation are shown in Table 2-5. By comparing Tables 2-2 and 2-5, the release dependence of solid fission products on temperature can be seen. It is also evident that with increasing operation temperature, the accumulation of long-lived activities on component surfaces located in the hot-gas circuit may present problems in maintenance work with helium turbines or process heat installations. Figure 2-7 shows the activities which may accumulate in the course of time in the primary circuit of the AVR outside the core at $950^{\circ} \mathrm{C}$. This is based on measurements and the assumption that all the activity released from the core with the hot gas plates out before it reenters the core with the cold gas. The contribution to a gamma dose from the activity accumulation is shown in Figure 2-8

The various components in the primary circuit were affected only slightly by the increase in temperature. Figures 2-9 and 2-10 show a compari- 
TABLE 2-5

CONCENTRATIONS OF SOLID FISSION PRODUCTS

IN AVR AT $950^{\circ} \mathrm{C}$ OPERATION

CONCENTRATION IN $10^{-9} \mathrm{Ci} / \mathrm{gm}^{3}$

ISOTOPE HOT SECTION COLD SECTION

$\mathrm{J}-131 \quad 28.3$

$\begin{array}{lll}\operatorname{Cs} 134 & 2.1 & 0.77\end{array}$

$\begin{array}{lll}\text { Cs137 } & 1.17 & 0.80\end{array}$

$\begin{array}{llr}\text { Agl10M } & 15 & 1.5\end{array}$

$\begin{array}{lll}\text { Ag111 } & 1350 & 60.8\end{array}$

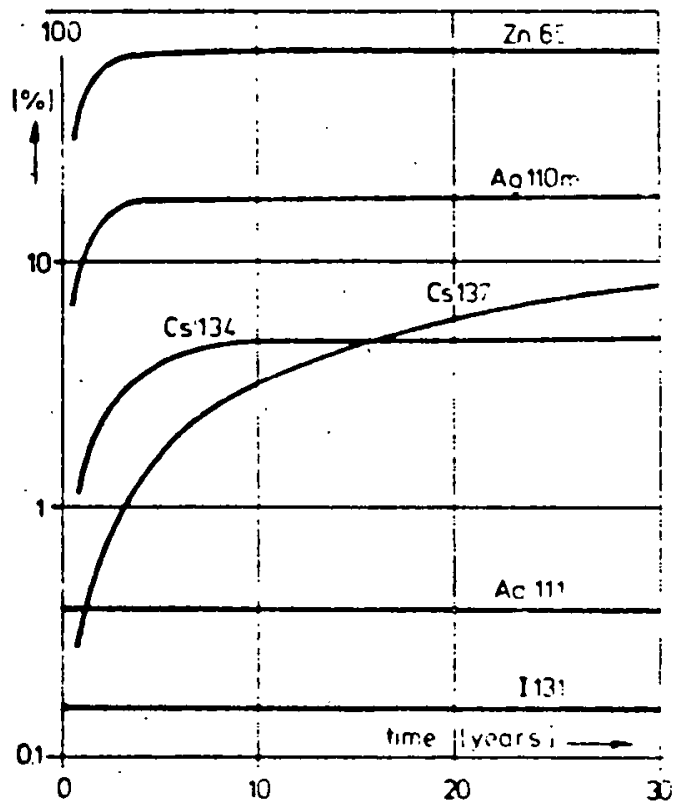

Figure 2-7. $\gamma$-Dose Rate Shares (\%) of Released Fission Products in the AVR Reactor

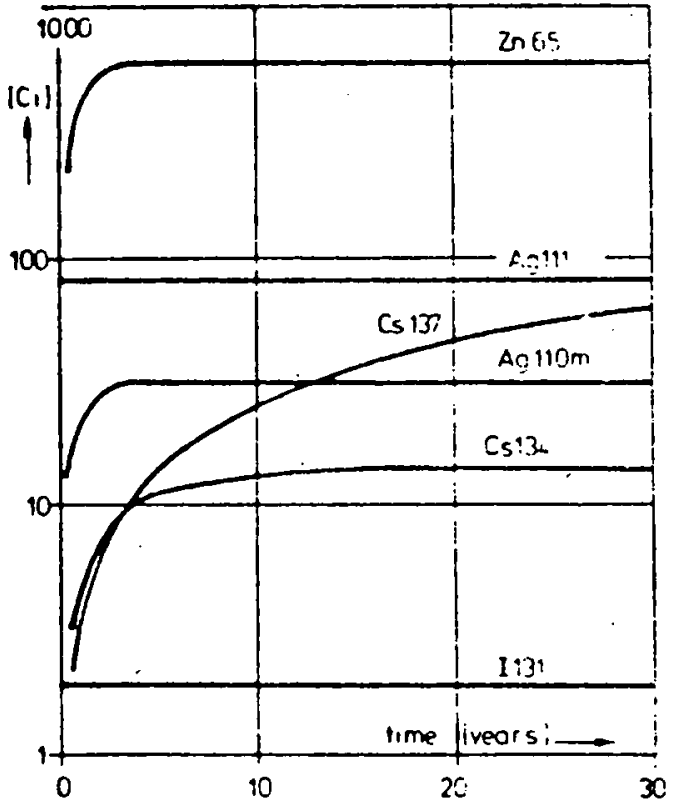

Figure 2-8. Activity of Released Fission Products in the AVR Reactor

son of average temperatures along a vertical and a horizontal cross section of the AVR. The only negative aspect of the experience under increased temperature conditions has been a failure of the nickelchrome-nickel thermocouples in the hot-gas duct area. The permanent loss of these thermocouples has made it difficult to determine the hot-gas temperature accurately, and impossible to measure directly the local temperature gradient in the upper structural ceiling. 


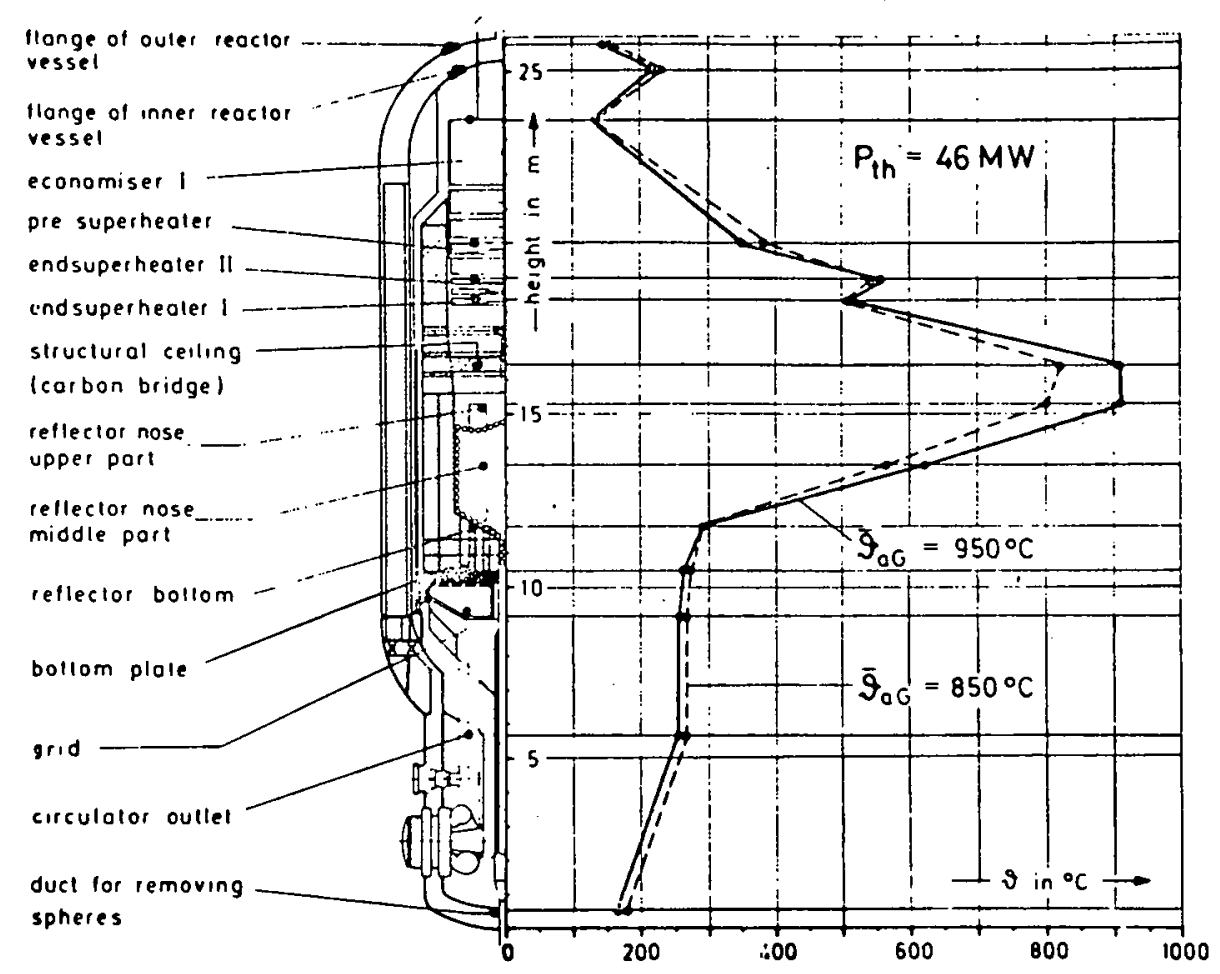

Figure 2-9. Temperatures in a Vertical Cross Section Across the AVR at 850 and $950^{\circ} \mathrm{C}$ Average Hot-Gas Temperature

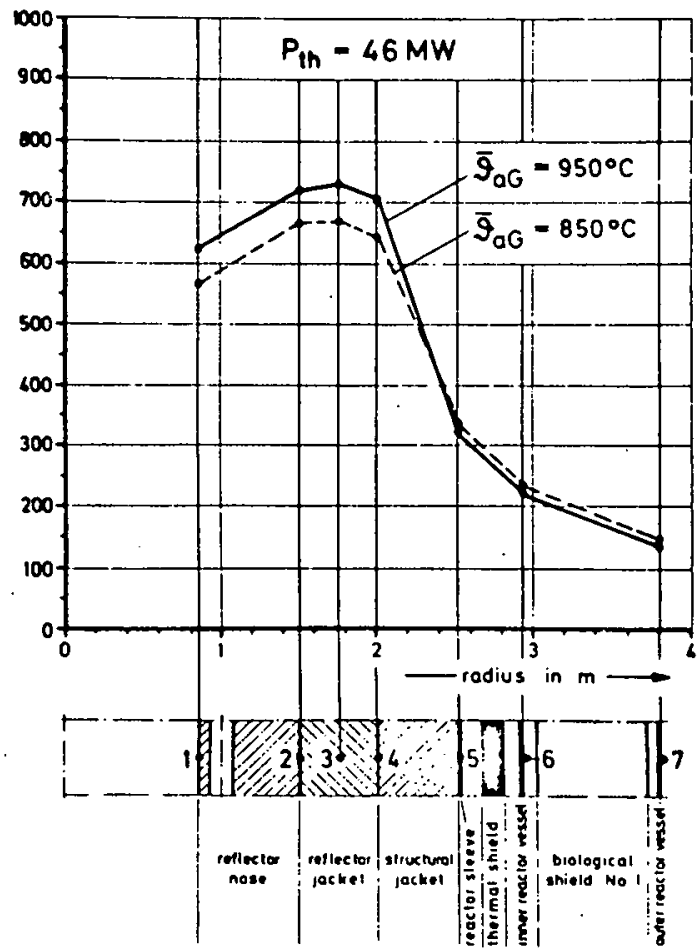

NOTE:

Measuring Points:

1. Reflector Nose, Middle Part

2. Inside Reflectior Jacket

3. Middle Reflector Jacket

4. Outslde Reflector Jacket

5. Reactor Sleeve

6. Inner Reactor Vessel

7. Outer Reactor Vessel

Figure 2-10. Temperatures, in a Horizontal Cross Section Across the Center of the AVR Core at 850 and $950^{\circ} \mathrm{C}$ Average Hot-Gas Temperature 
SECTION 3

DRAGON REACTOR EXPERIMENT

The Dragon Reactor was constructed to demonstrate the principles on which the High Temperature Reactor is based, and to undertake a research and development program concerned with the evolution of the commercial HTR, primarily in the area of power reactor fuel and fuel element testing. It achieved criticality in August 1964, and full power operation in mid-1965. During its life, it has accumulated the equivalent of over 2000 days at.nominal full power: The reactor description, operating experience, and comment have been selected from References 10-14.

\subsection{DRAGON REACTOR DESCRIPTION}

The Dragon is a $20 \mathrm{MW}$ helium-cooled reactor operating with an upper coolant temperature of $750^{\circ} \mathrm{C}$. The heat produced is rejected to the atmosphere by means of air-cooled heat exchangers. The core is composed of 37 replaceable fuel elements and has an hexagonal profile. Each element is seated on a spike on the core bed plate, through which a helium purge can be drawn to remove and monitor any fission products released from the fuel. Each fuel element consists of a cluster of seven hexagonal fuel rods of graphite, coolant channels being provided by raised ribs down the center of each face of the hexagon. A solid graphite portion at the top and bottom of the rods acts as reflector. The radial reflector is in two portions, fixed and removable.

Control is by means of 24 control or absorber elements which are constructed of concentric stainless steel tubes packed with boron carbide. They are located around the circumference of the core, moving in holes in the "removable" portion of the reflector. Control rod drives are located in positions of comparatively low temperature. The control rod arrangement is shown in Figure 3-1. 


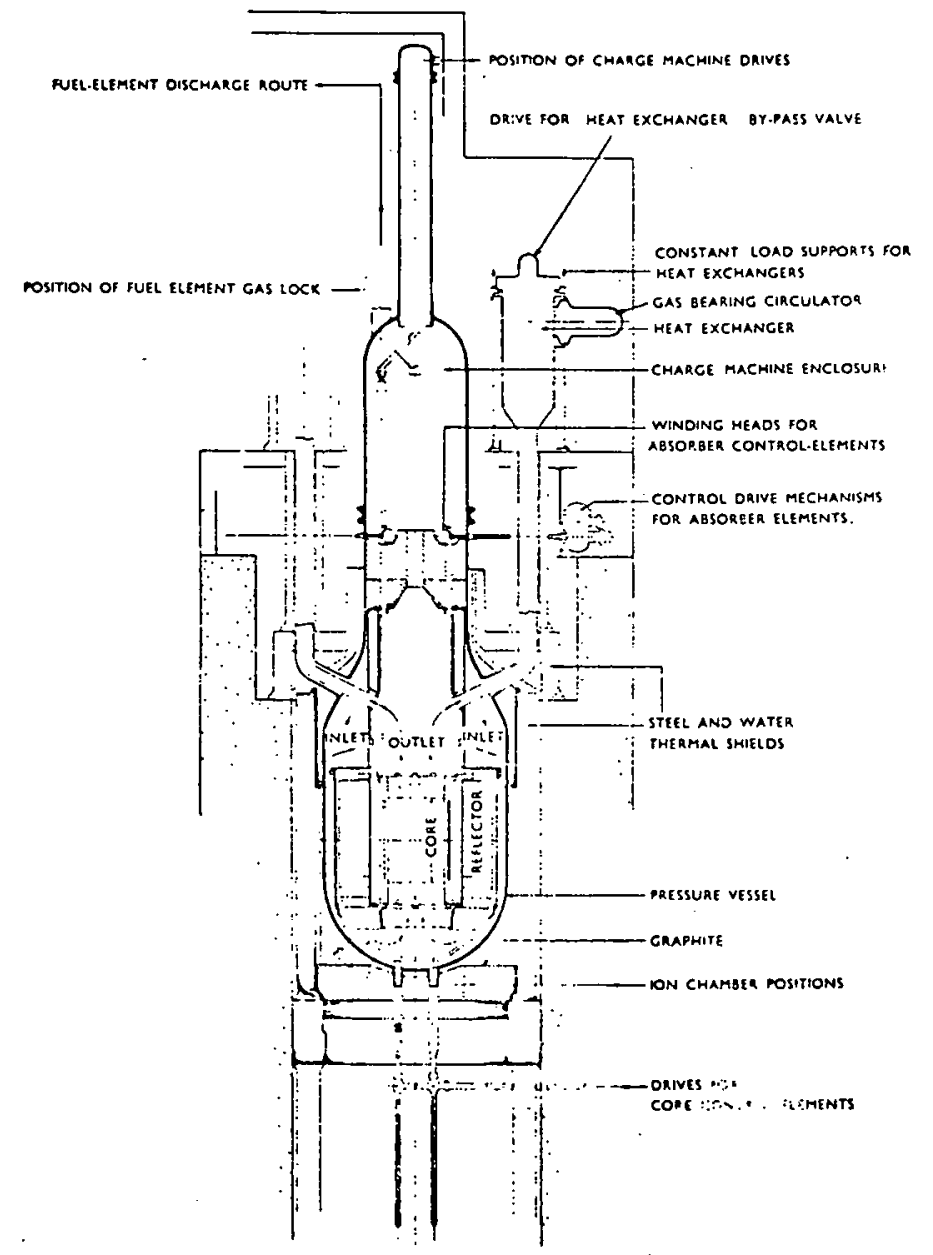

Figure 3-1. Control Arrangement of the Dragon Core

The reactor vessel is of unusual shape, taking the form of a main cylindrical portion $3.5 \mathrm{~m}$ in diameter, containing the core and reflector, with a "lower neck" $1.9 \mathrm{~m}$ in diameter, which is large enough for the charge machine to cover all of the core and movable reflector. Above this is an "upper neck" $0.61 \mathrm{~m}$ in diameter which contains the charge machine. The thickness of the main portion and lower and upper necks are, respectively, $57.2 \mathrm{~mm}, 38.1 \mathrm{~mm}$, and $15.9 \mathrm{~mm}$, the design pressure being 350 psia.

Helium at 20 atm pressure is used as the coolant, the temperature range of the reactor being from $350^{\circ} \mathrm{C}$ at inlet to $750^{\circ} \mathrm{C}$ at the outlet. By the use of concentric inlet and outlet ducts, and heat-resisting lining, all parts of the pressure vessel are kept at lower temperature. Figure 3-2 shows a vertical section of the reactor indicating the coolant flow. There are six coolant 


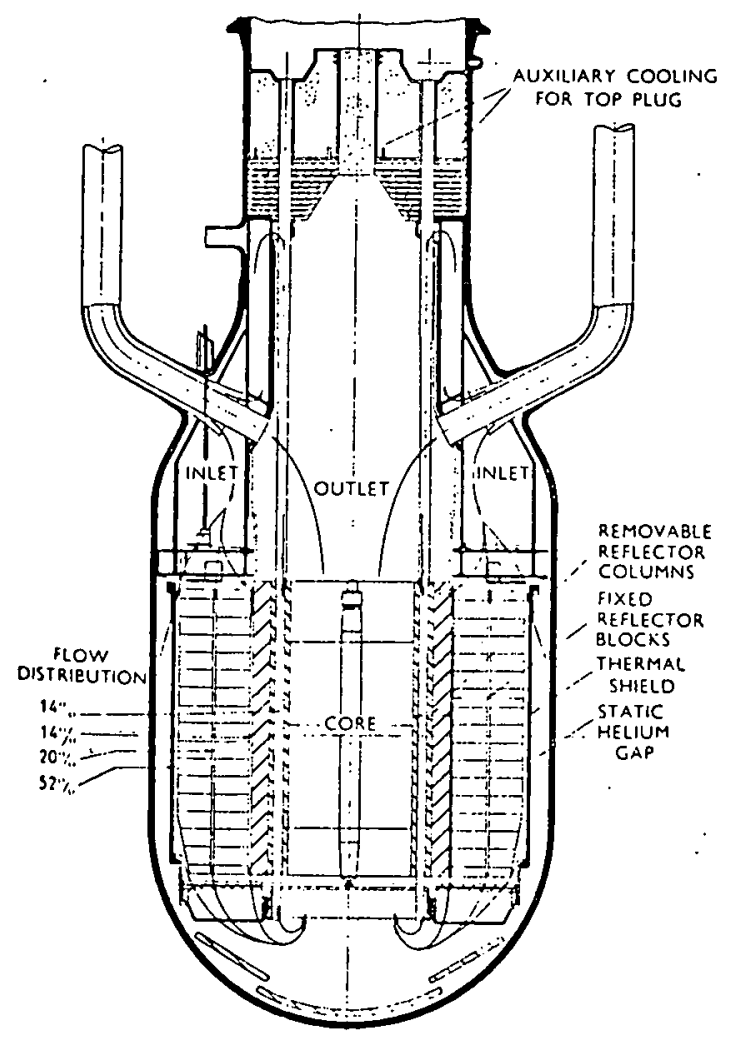

Figure 3-2. Section of Dragon Reactor Showing Coolant Flow

loops arranged radially around the reactor, each being complete with its own blower and primary heat exchanger. Each coolant loop is designed as a unit consisting of a circulator, a heat exchanger, and a bypass valve. The general arrangement is shown in Figure 3-3.

Fuel handling in the Dragon reactor is accomplished after the reactor has been shut down and cooled off. The fuel grappling machinery is permanently located within the upper bell-shaped portion of the reactor vessel. The fuel handling operations are performed remotely from the charge-machine control room in the outer concrete containment building by means of television and optical viewing systems.

The general arrangement of the Dragon reactor plant is shown in Figure $3-4$. 


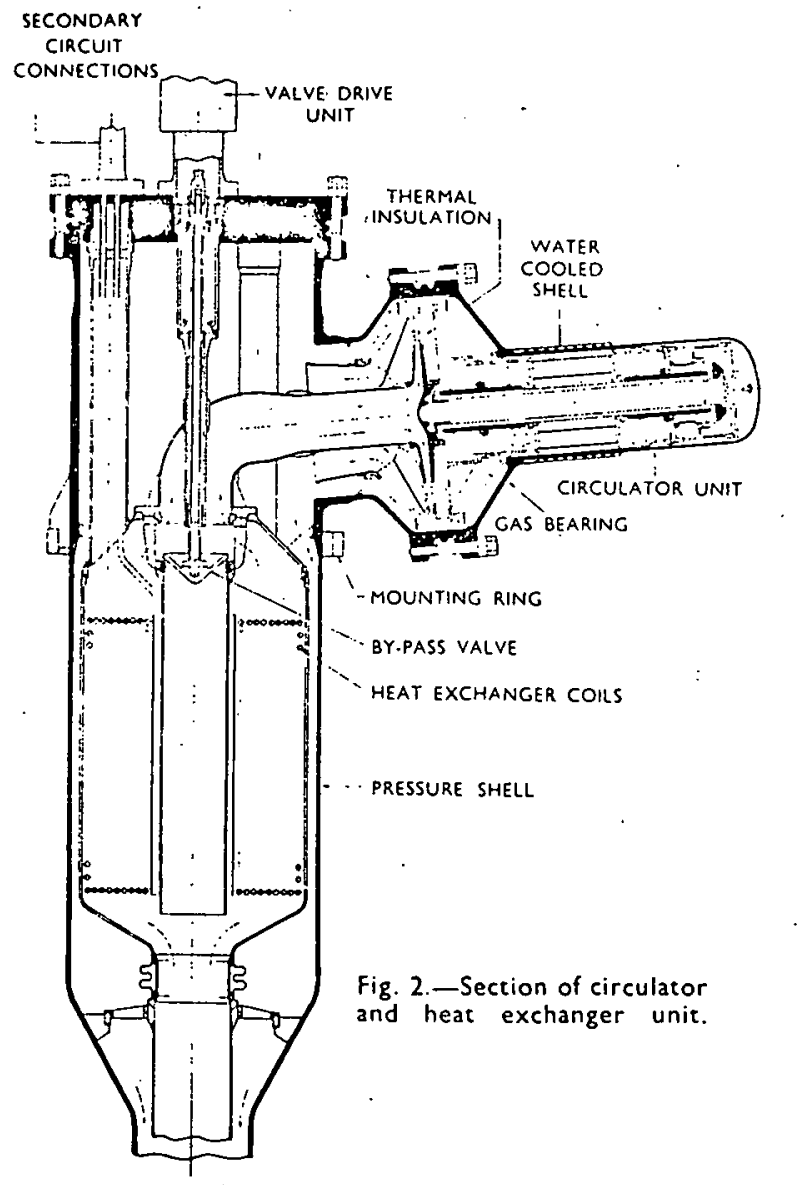

Figure 3-3. Section of Circulator and Heat Exhanger Unit

\subsection{DRAGON REACTOR EXPERIENCE}

\subsubsection{SUMMARY}

The experience from the Dragon experiment has been positive, both in terms of demonstrating HTR characteristics, and in conducting fuel research and testing of fuel elements appropriate for power reactors.

The fuel element arrangement allowed continuously evolving fuel element designs to be tested and evaluated, from the AVR spherical elements, to the "pin-in-block" type specified for the Mark III U.K. gas-cooled reactors, to the "integral block" type specified for General Atomic Company designs for. future U.S. commercial HTGR reacturs. 
1. Reoctor Core

Inner Steel Contoinment Shell

3. Outer Concrete Containment Shell

4. Primory Heat Exchonger

5. Coolant-Gos Circulator

6. Secondory Heat Exchangers

7. Control Rods

8. Control-Rod Drives

9. Fission-Product Purge-Gos Monifold

10. Fission-Product Removal and Helium Purificotion Plont

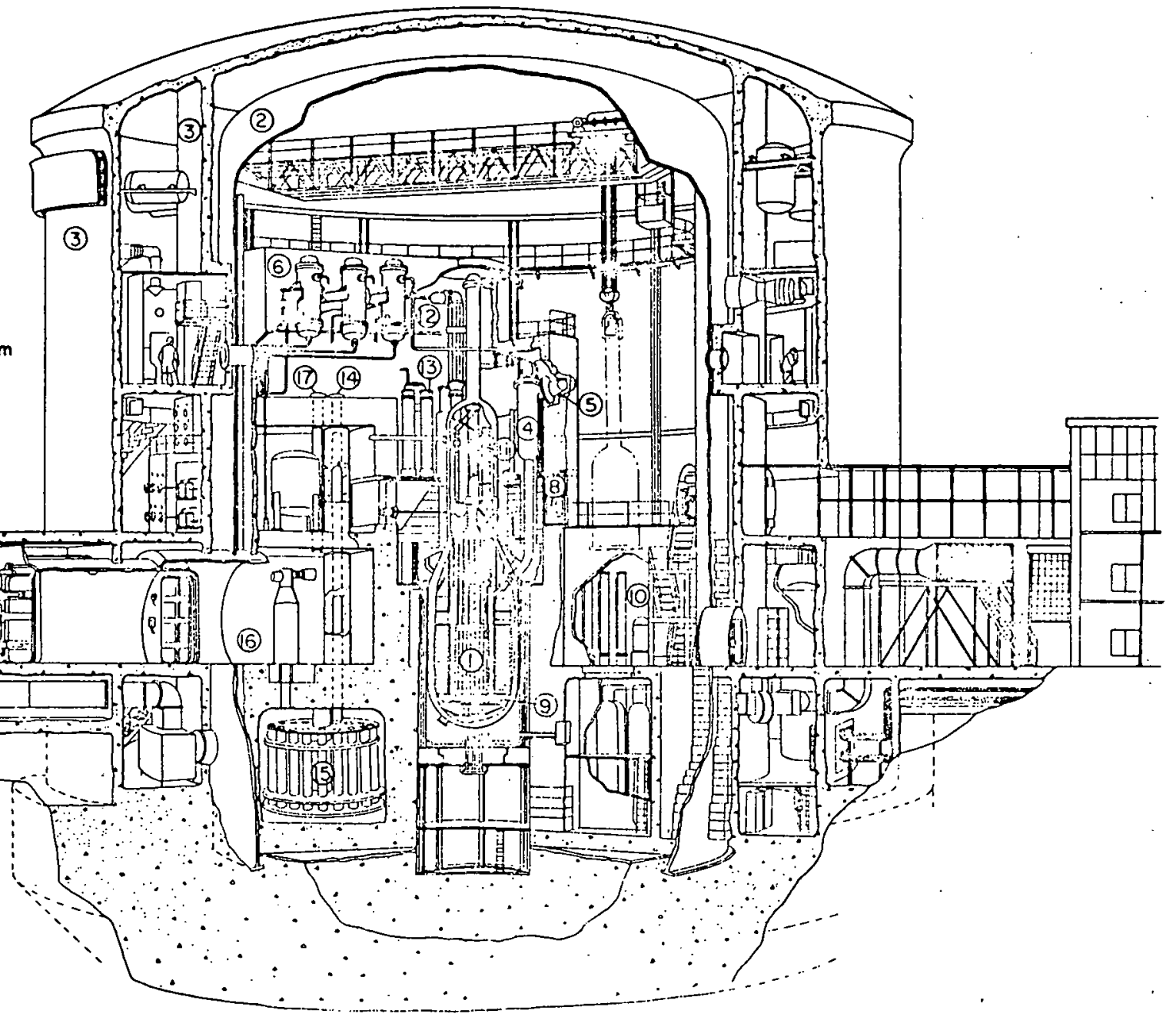

Figure 3-4. General Arrangement of Dragon Reactor Plant 
The reactor has demonstrated the inherent stability and safety of the gas-cooled reactors against transients and the ability to respond to large power fluctuations with relatively small temperature variations in the fuel.

In the area of fuel particle development, it demonstrated their excellent fission product retention capabilities, and was used to determine fuel particle performance limitations. Throughout the operation it maintained low concentrations of impurities and gaseous fission products in the coolant gas as well as low contamination levels from solid fission products.

Reactor component performance was good in general, although failures occurred in the primary heat exchangers (not normally HTR "power" reactor equipment) and in-core instrumentation thermocouples.- Nearly problem-free operation was achieved by the helium circulators.

The operation has demonstrated the strength of graphite structures both from the mechanical (handling) standpoint and with respect to thermal and irradiation behavior. A highlight of the Dragon operating experience has been the ease of access and handleability of components during maintenance due to low levels of contamination.

\subsubsection{CORE AND FUEL PERFORMANCE}

The original fuel element design of the fully purged, seven-rod cluster assembly evolved continuously to designs more flexible for testing power reactor fuel elements. The first variation was a design where the outer six tubes, containing unpurged driver fuel, could be separated from the center tube. In this arrangement the center tube could be purged and could accommodate test fuel for irradiation times irrespective of the lifetime of the driver fuel. In later designs, the fuel rod clusters were replaced by block-type fuel elements of comparable cross section. Initially, these elements were of the "pinin block" type and later of the "integral block" type. Figure 3-5 shows the evolution of fuel element design for the Dragon Reactor.

Early in the operating experience of the Dragon Reactor, the ability of the reactor core to respond to power variations with little change in fuel temperatures was demonstrated. 
D1 The original version with low permeability graphite and metal end features. None were Irradiated.

The first elements used having low permeabllity graphite and metal reinforced graphite bolts joining the rods to the top block. Internal fission product traps at the bottom of each rod; all of which were purged.

D3 Permeable graphite, no internal fission product traps, all rods purged. Uniform fuel throughout.

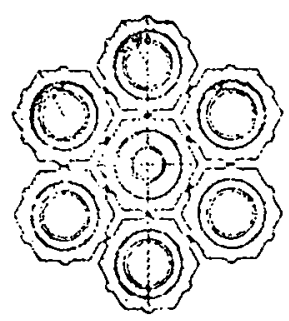

D1-D4

Experimental fuel in centre rod, outer six.rods unpurged driver fuel. A variant was used with coolant flowing through the fuel in the outer six rods as well as over the outside.

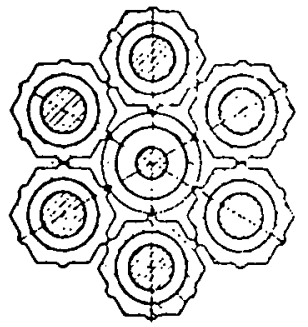

Experimental fuel in purged centre rod to which all six thermocouples are fitted. Outer six rods with driver fuel can be changed allowing centre rod to continue for long duration.

D12 A modification to the D5 outer six driver rods in which coolant passes through the centre of the fuel bodies as well as over the outside of the tubes.

$\mathbf{D B}$

GH/KSH test element. Increased diameter experimental centre rod accomodated by outer six driver rods of modified profile.

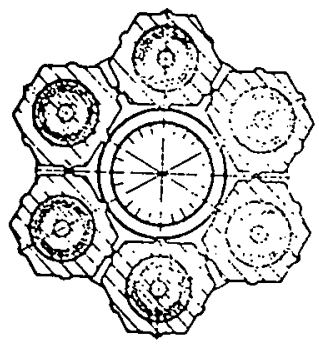

D9 llar to De but with centre rod containing spheres for THTR. Heat generated in the spheres was conducted through a graphite tube to the coolant and a purge flowed over the spheres to monitor fission products.

$D 8$ and D9

A power reactor pin test element with 18 tubular pins arranged in a pattern of $\mathrm{six}$, three high around a centre graphite member. This

simulated the pin arrangement proposed for the heterogeneous HTR. Only one element of this type was

1 rradiated.
D7 Multi annulus element. Test of a proposal for power reactor element.

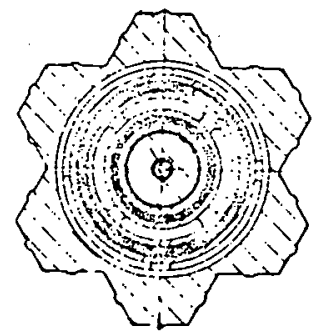

D14 Th1s element was designed to test the pin-1n-block concept for the homogeneous HTR. Nine pins are contained, three in each channel. Thermocouples can be positicned In any of the pins or the coolant channels and provision can be made to sample the coolant at outlet.

only a limited number of elements of this type can be accommodated in the Dragon Reactor since they have less than the average fissile material content and generally a high fertile material loading giving an overall react-

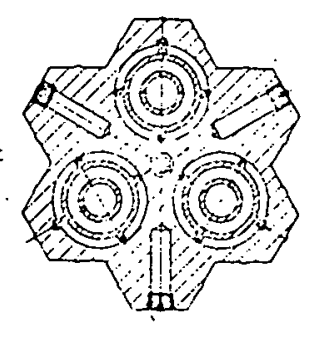
ivity penalty.

Figure 3-5. The Development of Fuel Elements

for the Dragon Reactor 


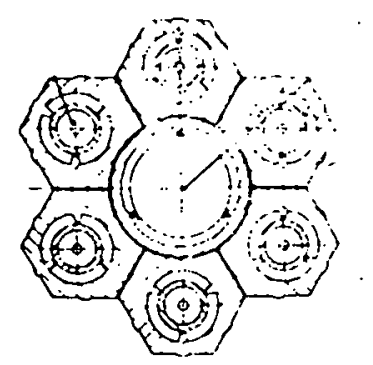

15 The third type of sphere test element in which the spheres are directly cooled and carried in a tube simliar to an enlarged D5 centre rod. The special driver cluster can be changed.

D16 A carrier block with seven channels, the outer six carrying driver pins of tubular interacting type which can be changed at intervals by a pin changing machine at the reactor. The centre channel of $68 \mathrm{~mm}$ dianeter contains experimental specimens generally of tubular form. Fission product sampling from the centre channel outlet collant can be incorporated and thermocouples can be positioned in the centre channel.

D17 A variant of the D16 body in which the centre channel contains purged tube of DS type. The D17 body can continue Irradiation for long times with regular changes of driver and experimental fuel. It is a valuable test of a large monolithic graphite block.

D21 As the Di6 but incorporating stainless steel mesh fllters at entry and exit from each cliannel to allow the testing of fuel bodles with a risk of particles becoming loose, for example directly. cooled moulded pins.

D18 A power reactor pin test in which seven identical channels each contain three pins of hollow rod form. Another element with a high reactivity penalty.

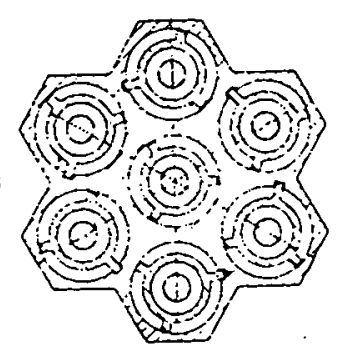

D 20

A special carrier to provide $75 \mathrm{~mm}$ diameter channels to test six pins to the UKAEA Tubular Interactirg Reference Design Specification.

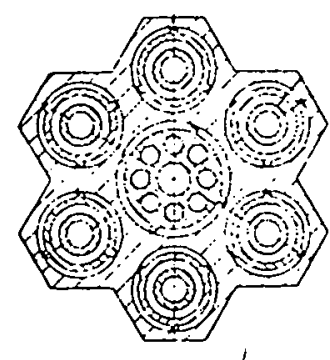

D19 A driver pin test element comprising a cluster of seven tubes each simulating a driver pin channel for a D16 type element. Thermocouples can be incorporated in any channel.

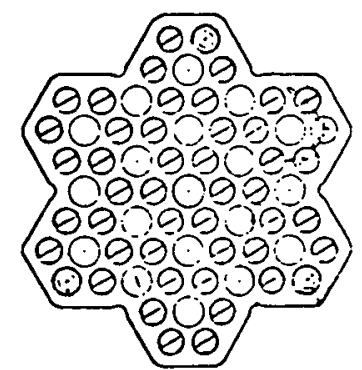

D22

The first integral block fuel element based on the Fort St Vrain block geometry. Two blocks $740 \mathrm{~mm}$ high and one $167 \mathrm{~mm}$ high are stacked between end features to direct the coolant and facliltate handling.
D23. A carrler hollowed out to acconmodate a section cut from a moulded integral block. Stainless steel mesh fllters are provided at top and bottom of the carrler.

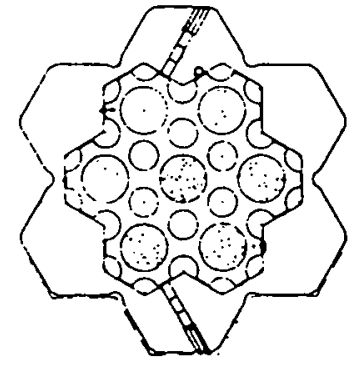

D25' Integral block tests with the General Atomlc $1160 \mathrm{MW}(c)$ Power Reactor geometry or UK Reference Integral Block geometry.
D24 A driver fue: $\cdots:$ test element in which a tube carry: ; inree pins is fitted in the central civity of a D16 block. Thermocouples measure $p$ in and coolant temperatures.

Figure 3-5. (Cont'd) 
Figure 3-6 shows a typical slow transient carried out on the Dragon Reactor by variation of the coolant flow. The control rods were kept fixed throughout. It can be seen that a power reduction of $30 \%$ was made by reducing the coolant flow by $49 \%$ : The net result of a small rise in coolant temperature is the drop in heat transfer coefficient and relatively small differential temperature in the downward direction. This is many times less than the equivalent change in other reactor systems.

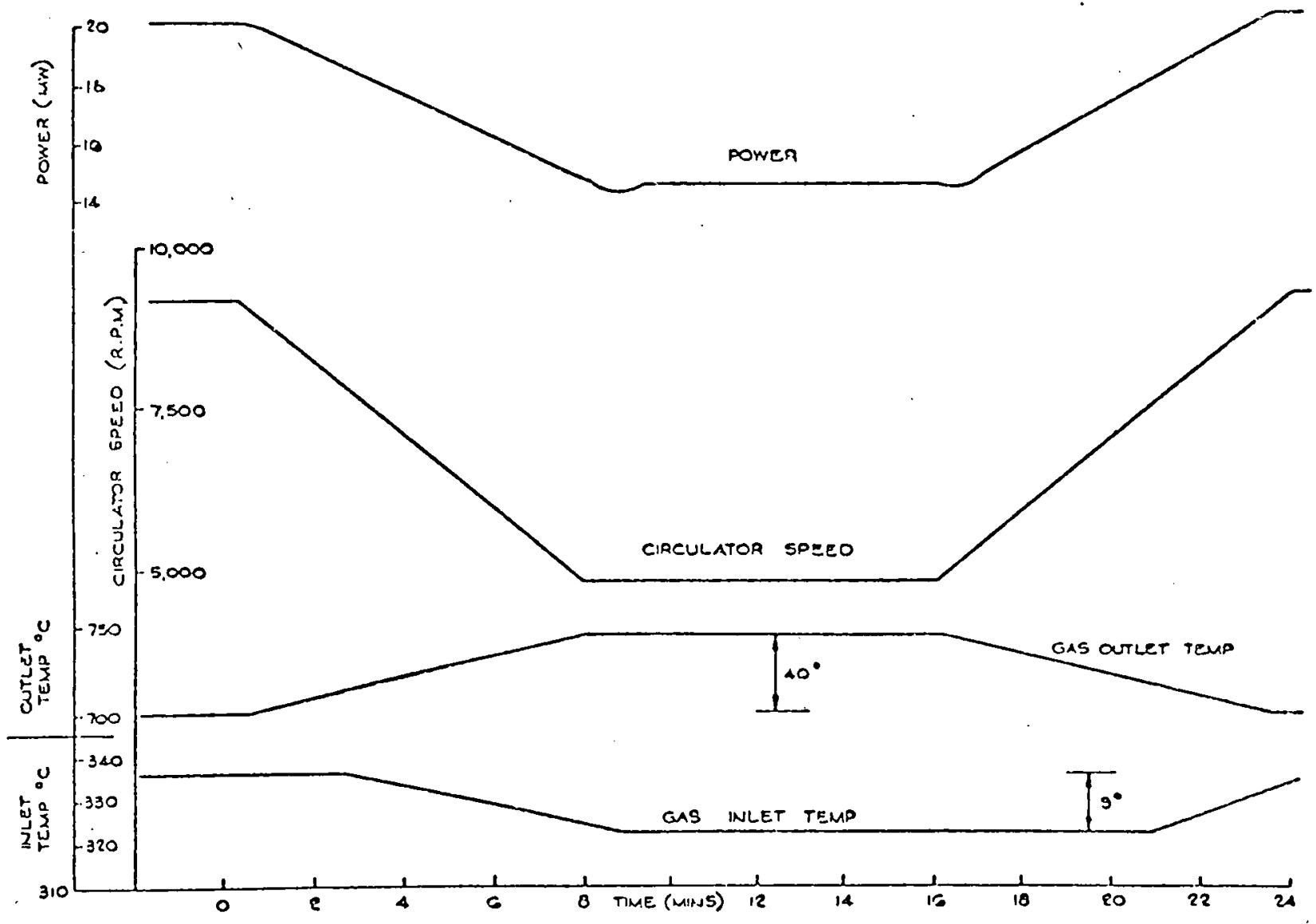

Figure 3-6. Dragon Reactor - Coolant Mass Flow Transient

Another test was carried out to demonstrate the effect of a sudden demand for power output. The blower speed was increased rapidly with.fixed control rod positions. As can be seen in Figure 3-7, the power to the heat exchangers closely matched the mass flow since the gas exit temperature fell only slightly. Most noticeable was the drop in graphite surface temperature as stored heat was picked up. This in turn produced a power increase which in $35 \mathrm{sec}$ had matched the new demand and increased the fuel to surface 

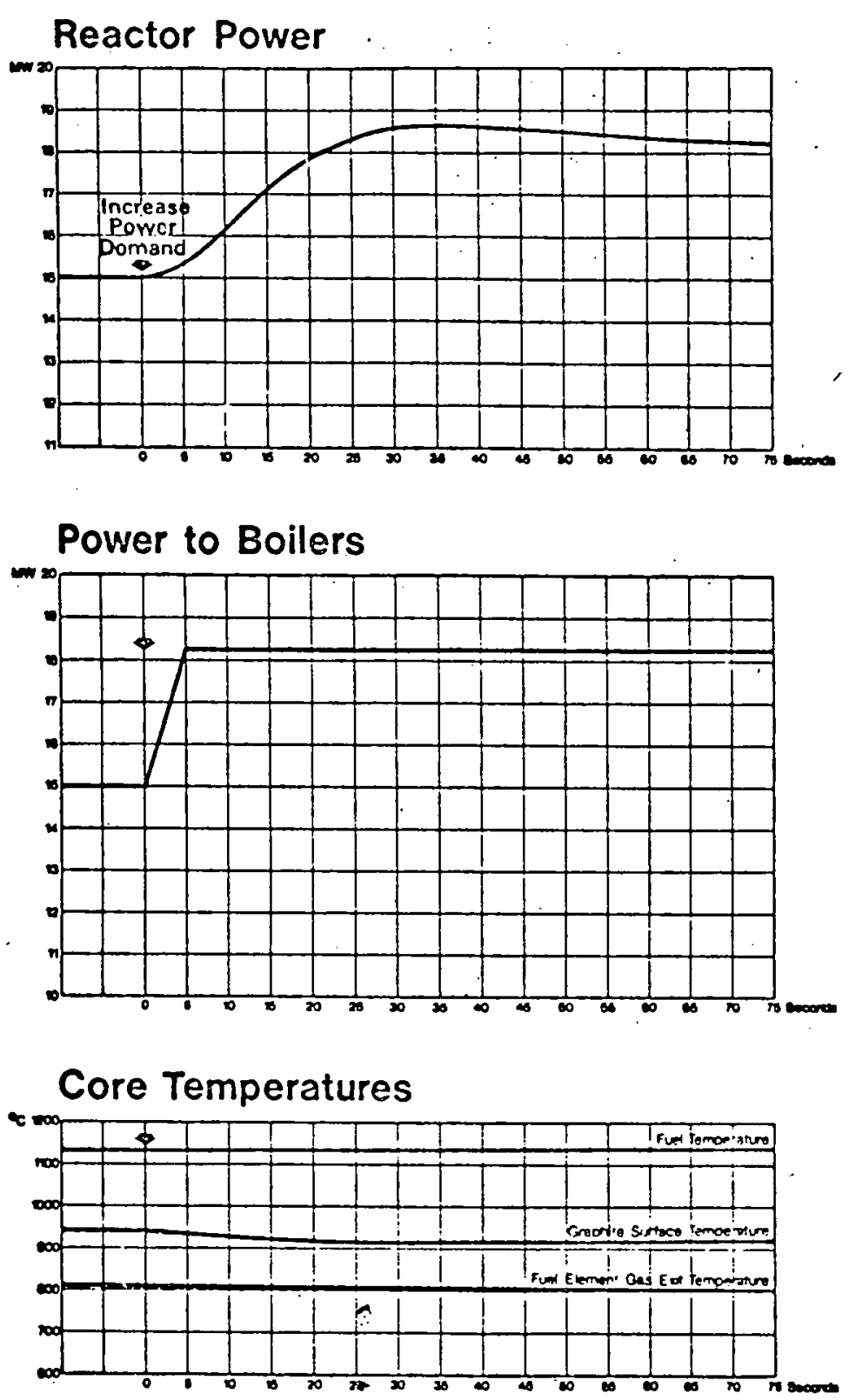

\section{Core Helium Mass Flow}

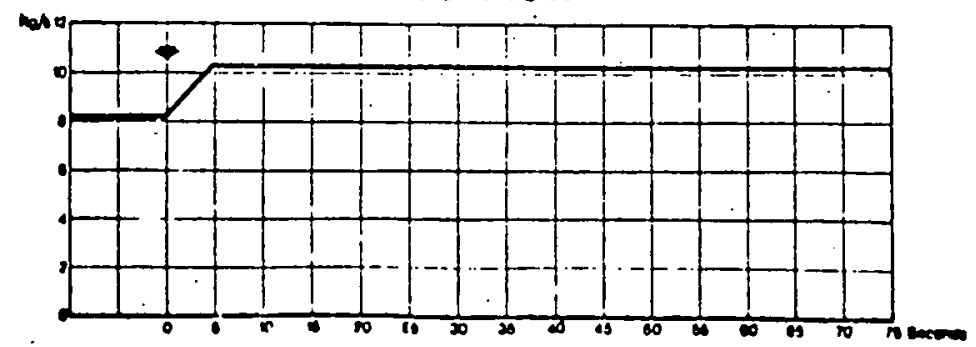

Figure 3-7. Reactor Response to Fast Load Pickup from $75 \%$ to $90 \%$ of Full Power 
temperature differential. The final result was a constant fuel temperature throughout the transient.

The results of a negative step by fast insertion of a control rod are shown in Figure 3-8. The very rapid power change is accompanied by slow and moderate temperature changes, the maximum fuel and coolant exit variations being about $280^{\circ} \mathrm{C}$ and $132^{\circ} \mathrm{C}$, respectively.

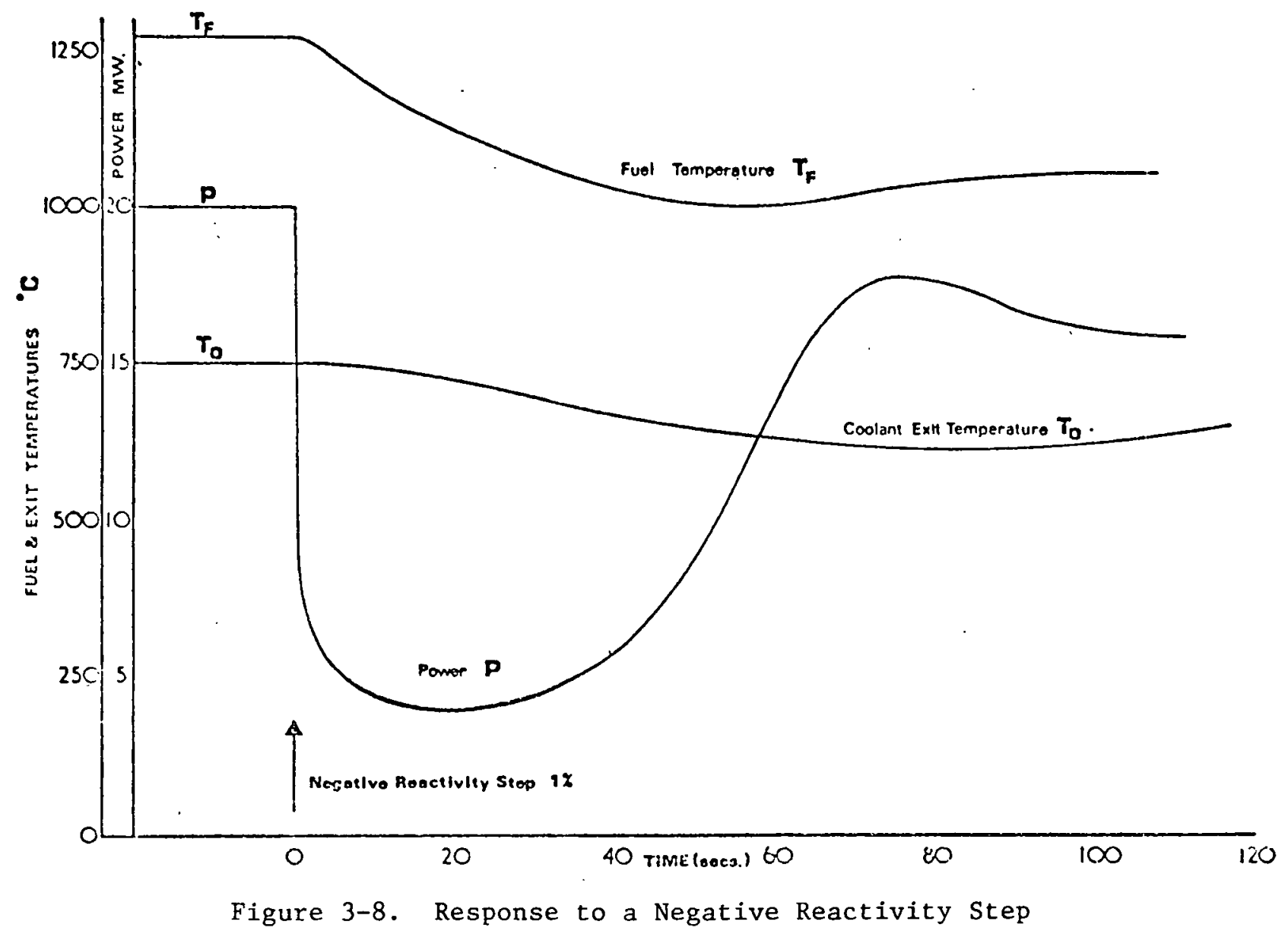

The very large number of fuel particles contained in an HTR element imply that a statistical approach is valid for failure prediction. The Dragon Reactor experiment has confirmed this approach, particularly in experiments in which fuel particles have been grossly overrun. Figure 3-9 shows the steady rise of activity release over 80 days when fuel typical of that designed for $1250^{\circ} \mathrm{C}$ operation was run at temperatures above $1800^{\circ} \mathrm{C}$. The significant feature is the exponential increase in release, indicating that in the case of unexpected fuel failure, there would be a slow buildup of activity permitting location and removal before it became an operational problem. 


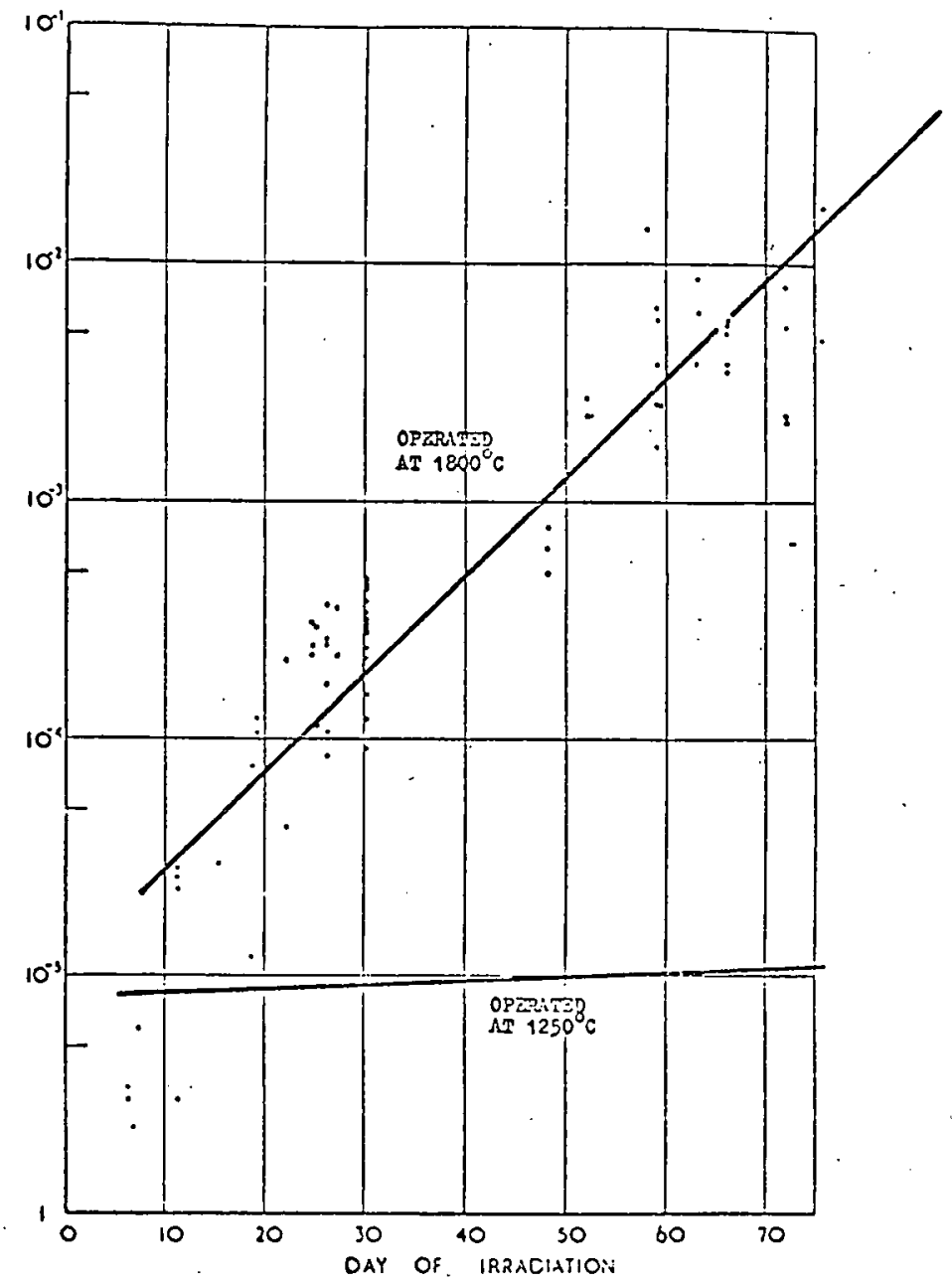

Figure 3-9. Variation of Xe 133 Release/ Birth Ratio with Time

A substantial part of the Dragon Reactor experiment was the program devoted to research and development of fuel particles. The program contained manufacturing, irradiation, post-irradiation examination, and evaluation of fuel particles developed for the Dragon driver fuel and expérimental fuels. .

The driver fuel particles contained hafnium-free zirconium as the diluent in the first charge. Subsequent to that, the diluent had been carbon with a PyC/SiC/PyC coating employed, the atomic ratio of U-235:C being 1:11. The fuel particles showed excellent performance at high temperatures and have survived $70 \%$ (ITMA) burnups at $1200^{\circ} \mathrm{C}$. Typical driver fuel temperatures were $1450^{\circ} \mathrm{C}$, but there is evidence that some have been subjected to as high as $1650^{\circ} \mathrm{C}$. No significant breakage of driver fuel. cccurred, so the fission product release was dictated the initial free uranium fraction which is typically 
$0.5 \times 10^{-4}$. The studies of experimental fuels were focused on kernels with mixed uranium-thorium composition in carbide or oxide. Coatings were PyC/SiC/PyC or just PyC. In 1966 the so-called Dragon Reference Fuel Particle was devised to act as a focus for the in-depth study of the performance limitations. The phenomena which eventually limit performance were identified to follow three categories, (i) pressure failure, (ii) fast neutron-induced PyC cracking, and (iii) chemical deterioration (amoeba attack). The pressure buildup in the particle is due primarily to $\mathrm{Kr}$ and $\mathrm{Xe}$ isotopes produced during fission. To a lesser extent in oxide fuels, some buildup is due to co formed from reaction between released oxygen and carbon. The coatings provide containment of the gases and will fail when their strength is exceeded. The strength of the coating is limited by the interaction of PyC and SiC. The SiC acts as a restraint on the PyC which has the tendency to shrink under the influence of fast neutron irradiation. The PyC suffers a "creep strain" through this restraint. Figure 3-10 shows qualitatively the mechanical endurance for coated particles.

The chemical deterioration known as "amoeba attack" is thought to be the internal mass transport of carbon from the hotter side of the particle to

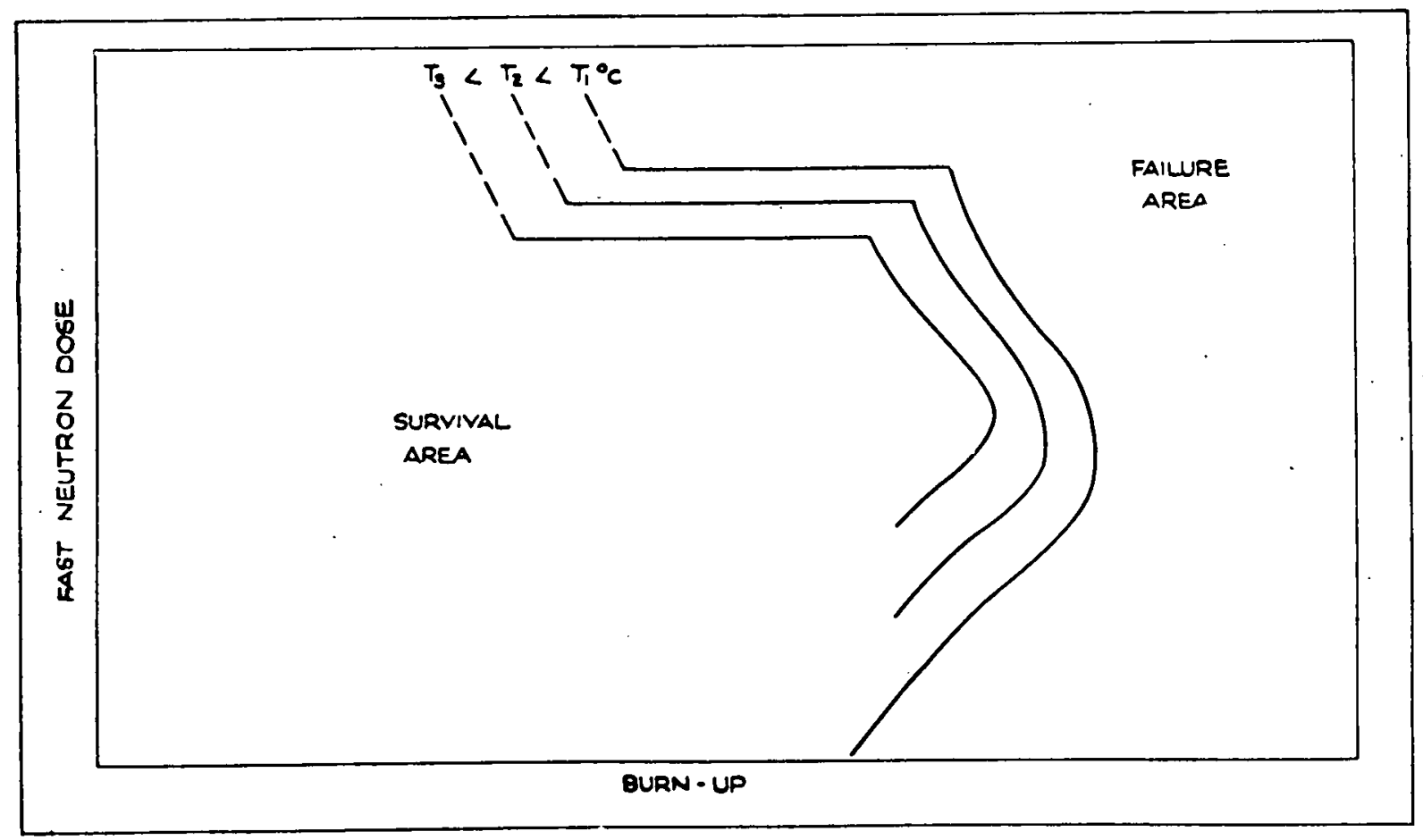

Figure 3-10. Mechanical Endurance Diagram for Coated Particle Fuels 
the cooler side. Experimental work studying this phenomenon has been carried out.

A large body of experimental data has also been accumulated on ifission product migration through intact coatings. It has been demonstrated that SiC in high-density layers as a barrier to metallic fission products can be considered completely impermeable to $\mathrm{Cs}$ and $\mathrm{Sr}$ throughout reactor lifetime at temperatures of $1250-1350^{\circ} \mathrm{C}$. Increases in diffusion rates do occur, however, if the deposition conditions are made to produce coatings containing excess silicon.

\subsubsection{COOLANT GAS}

The chemical impurities in the helium gas have been comparatively insignificant in terms of gross surface corrosion. They can be important, however, because of their effects on metals. The purity of the coolant in the Dragon Reactor has been maintained by a purification system which has kept the impurity concentration very low. Typical values of impurity concentrations in helium of the primary circuit are

$\begin{array}{ll}\mathrm{CH}_{4} & 0.1 \mathrm{vpm} \\ \mathrm{CO} & 2.0 \mathrm{vpm} \\ \mathrm{CO}_{2} & 0.2 \mathrm{vpm} \\ \mathrm{H}_{2} \mathrm{O} & 0.04 \mathrm{vpm} \\ \mathrm{H}_{2} & 1.5 \mathrm{vpm}\end{array}$

Unaccountable helium losses in the Dragon. Reactor were kept within the design target of $0.1 \% /$ day $(0.2 \mathrm{~kg} / \mathrm{day})$ during the first years of operation. It was reported in 1972 that leakage rates of $0.1 \%$ /day are easily achievable. In June 197,4 the average leakage rates were twice as high as in the years before 1974. One major source of the increased rates was found in the stainless steel pipework leading to the helium purification plant. The leaks were produced by chloride corrosion in sections of the pipe that were wrapped with PVC insulating tape for marking purposes. Elimination of this source brought down the leak rate to $0.2 \mathrm{~kg} /$ day for a short period of time until $0.7 \mathrm{~kg} / \mathrm{day}$ losses were encountered again. In general the majority of leaks in Dragon have taken place on the small-bore pipework being mechanically damaged during maintenance of larger components. Unlike the experience previous to 1972 , it has taken considerable effort to keep leakages within the target $0.1 \% /$ day. 


\subsubsection{RFACTOR COMPONENTS AND MATERIALS}

\subsubsection{Valves}

Valves are by far the most numerous mechanical components. The total fault rate for main valves between $1966-1971$ was $7.8 \% /$ year, with helium valves representing a fault rate of $8.6 \%$ /year and nitrogen valves $4.8 \%$ /year. Although these fault rates have been acceptable, the performance has not been as good as the performance of the soft-seated "Nupro" instrumentation valves which have shown a fault rate of less than $0.25 \%$ /year.

\subsubsection{Circulators}

The six primary $100 \mathrm{hp} \mathrm{circulators} \mathrm{fitted} \mathrm{to} \mathrm{the} \mathrm{Dragon} \mathrm{have} \mathrm{given} \mathrm{a} \mathrm{re-}$ markable demonstration of reliability of gas-bearing machines. Up to 1972 , over 200,000 machine hours were accumulated, and no fault occurred in service with the reactor at power. Some faults have occurred at minimum idle speed (1500 rpm) and low circuit pressure. It is characteristic of the gas-bearing type that a machine would experience the most difficult test at startup and idle-speed operation. If it starts satisfactorily, there is a high confidence level in its integrity for normal high speed duty (9000 rpm).

\subsubsection{Thermocouples}

Dragon has a large number of thermocouples installed in the core and primary circuit. The performance and durability of the metal-sheathed $\mathrm{Cr} / \mathrm{Al}$ couples monitoring the circuit structure and reflector have been excellent. The performance, however, of the in-core couples was not satisfactory. In particular, Cr/Al couples in the core, used to about $900^{\circ} \mathrm{C}$, failed at a rate of $20 \%$. W/WRe couples used for fuel temperatures of $900-1400^{\circ} \mathrm{C}$ failed extensively. Post-irradiation examination has not shown any significant corrosion attack on the sheaths and the failures are attributed to problems associated with manufacture and installation.

\subsubsection{Graphite}

The exposure of the graphite in the Dragon Reactor to water and carbon monoxide (integrated over time) has been far higher than would be typical of a commercial system because of the experimental use of Dragon to study chemical 
reactions of helium-borne impurities. Even so, the reductions of dimensions of graphite, although measureable, has been almost insignificant in relation to strength requirements.

\subsubsection{Metals}

The only instance of metal failure in the Dragon primary circuit has been the reflector block tie link system. These links were not designed to carry any significant load, but became highly stressed as a result of operating the reflector blocks for several times their design life. The significant fact is that examination of the fractured links showed a typical long term strain creep failure completely in line with the calculated stress/time relationship and the normal engineering data of Monel 400 material. There had been no deterioration of the material and no corrosion attack after 32,000 hours at about $520^{\circ} \mathrm{C}$.

A number of metal components have been removed from the circuit and have been studied metallurgically. Of greatest interest are specimens taken from the hot coolant duct liners. These Nimonic 75 components show a $2 \mu \mathrm{m}$ oxide film with occassional fingers penetrating to $15 \mu \mathrm{m}$, and some recrystallization to a depth of $2.7 \mu \mathrm{m}$ after some 32,000 hours of service at a temperature of about $700^{\circ} \mathrm{C}$. Ductility of a test specimen was normal for the material in spite of a very slight increase of carbide precipitation.

\subsubsection{MAINTENANCE}

The fission product release studies, both gaseous and metallic, indicated that the primary circuit would be relatively clean. There were two opportunities during the operation of the reactor where the predictions were proven out. The first, in November 1969, involved the replacement of the heat exchangers. A1though the primary circuit conditions were at least as severe as those expected on a power HTR, no significant difficulties were encountered either in respect to the mechanical operations or the control of radiation.

The second major operation took place in 1973 and involved the reflector block replacement. Again no major problems were encountered due to radioactive contamination. Numerous devices such as television cameras, lights, handling tools, etc., were lowered into the core chamber, frequently rubbing against graphite and metal surfaces, yet on removal they showed very little contamination, requiring no personal protection other than normal industrial fabric 
gloves. The graphite block itself, which had been adjacent to the core for eight years, could be handled with ease showing a dose rate on the surface of about $200 \mathrm{mr} / \mathrm{hr}$. Gamma spectrometry employed on one of the reflector blocks showed the presence of predominantly Sc-46 and Co-60 and traces of Cs-134, Cs-137 and Ag-110m. Scandium and cobalt, which accounted for over $95 \%$ of the activity on the graphite, are not results of coolant transport. The scandium is a common impurity in graphite and its uniform distribution through the block indicates simple activation; cobalt is attributed primarily as a "pickup" of tool wear during machining. Thus only $10 \mathrm{mr} / \mathrm{hr}$ dose on the graphite surface is attributed to gas-borne activity deposition.

From the mechanical operations point of view, the reflector replacement experience showed that good viewing facilities facilitated the operation substantially. It has been suggested that a permanent system for regular direct viewing and survey photography should be incorporated in the design of future reactors. 
SECTION 4

ADVANCED GAS-COOLED REACTORS (AGR)

The advanced gas-cooled reactor (AGR) was introduced in the U.K. to take advantage of the $\mathrm{CO}_{2}$ experience gained with the magnox reactors. The design and development of the magnox reactors proved to be relatively easy, and the first AGR's were committed to construction with the technology backing of work done for a $30 \mathrm{MW}$ demonstration AGR at Windscale.

The two AGR's at Hinkley were brought to power in July 1976 and February 1977 respectively, and the first Hunterston reactor achieved $500 \mathrm{MW}$ in August 1976. A total of $10 \mathrm{AGR}$ reactors are expected to be operational within the next three years. Although the $\mathrm{CO}_{2}$-cooled $\mathrm{AGR}$ is intended for power production due to temperature limitations $\left(\mathrm{e} . \mathrm{g} .600^{\circ} \mathrm{C}\right.$ versus the $900^{\circ} \mathrm{C}$ required for a process heating system), it does have certain common futures with other high temperature gas-cooled reactors. The operating experience can be useful in the development of future HTGRS. The main common features are the gas circulators, the pressure vessels, and the use of high-temperature insulation systems. Some general comments on these features are given below.

\subsection{CIRCULATORS}

The circulators for almost all AGRs are fully encapsulated, that is, they operate entirely within the pressure circuit. However, all moving parts can be removed from the reactor and replaced on a routine basis. An important feature in the design at Hinkley was the isolating dome, incorporated so that the circulator compartment could be depressurized and the circulator replaced with the rest of the reactor circuit at pressure. The principal problems encountered have included machine vibration (both mechanical and aerodynamic), oil ingress to the reactor, gas leakage into the cooling water system, and mechanical problems associated with the dome operating system. Difficulties with the isolating dome arose from the choice of material for sliding pairs 
in a $300^{\circ} \mathrm{C}$ environment when high loads are involved and when fretting occurs while the components are stationary. As a result, the dome can no longer be used for high pressure isolation.

\subsection{SINGLE- AND MULTI-CAVITY PRESSURE VESSELS}

The AGR designs use concrete pressure vessels for containment with an integral gas circuit design in which the core, boilers, and circulators are all incorporated within the vessel. Two concepts have been used, single- and multi-cavity vessels. In the single-cavity construction at Hinkley, the boilers occupy an annular space provided between the core structure and inner liner of the vessel. Circulators, boiler feed, and steam tubes are arranged horizontally in the vessel walls. The multi-cavity arrangement has a core contained in the central cavity with the boiler units dispersed in vertical pods in the vessel. walls. Closures of a permanent form are fitted above each pod for insertion and removal of individual units. An appraisal of the alternative cavity layouts indicates better space utilization with the podded design, a more compact mechanical layout. Effective containment of high-temperature gas and the reduction of voids in the gas space are other attractions of the podded design. These features, however, are obtained at the expense of increased liner area and requirement for insulation. Whether the access afforded by the podded layout will be adequate has yet to be seen. In contrast, access in the single cavity layout is less restrictive, and has been used to good purpose throughout construction testing and commissioning for inspection and servicing of the majority of equipment located in the annulus.

Cavity layout also has a marked influence on gas flow pattern at the inlet to the boilers and around them. In the single cavity the flow of cold gas streams associated with the core refueling could give the boilers an unacceptable, nonuniform temperature profile at inlet, and it requires the introduction of control valves and mixing devices to give satisfactory gas temperature profiles. On the other hand, the inlet gas ducts of the podded design promote good gas mixing, and in conjunction with control valves provided at the feed inlets, prevent any gas maldistribution problems. Operational experience should show the merits of this appraisal. 


\subsection{INSULATION}

The liner temperature of gas-cooled reactors is 1 imited to about $75^{\circ} \mathrm{C}$ by insulation on the gas side of the liner and a water-cooling system on the concrete side. The insulation has to operate in a high pressure gas, and the hot face is exposed to surface pressure gradients and to high noise levels. The thermal problems are almost all related to controlling the gas movement within the insulation assembly. To reduce gas movements to a few meters per hour, the permeability of the insulation assembly must be of the order of $10^{-10} \mathrm{~m}$ for $\mathrm{CO}_{2}$. Permeability control has been achieved in the AGR's by the use of either metallic foils or ceramic fibers. The problems of the two insulants are different. Metallic foils give a very anisotropic performance with associated problems in penetrations and corners, and are very difficult to install on imperfect surfaces. Ceramic fiber insulants do not have these problems, but the fiber suffers from loss of resilience at high temperatures. Recent work on new fibers suggests that a satisfactory fiber will be available for helium applications.

The thermal performance of AGR types of insulation is very well understood, and it is unlikely that the increase in temperature or pressure of helium coolants will bring the insulating design outside the range already covered in AGR work. 
SECTION 5

THORIUM HIGH TEMPERATURE REACTOR (THTR)

\subsection{BACKGROUND}

As a result of the experience gained on the AVR Experimental Power Plant, the design for a larger pebble bed reactor for commercial use was prepared by Brown Boveri/Krupp Reaktorbau GmbH, now Hochtemperatur-Reaktorbau GmbH (HRB), in cooperation with the nuclear research center (KFA)Julich. This larger ( $300 \mathrm{MW}$ ) plant, designated the THTR, was ordered on July 30, 1970 by a group of utilities incorporated as the HochtemperaturKernkraftwerke-Gesellschaft (High Temperature Nuclear Power Plant Company or HKG). Construction of THTR was contracted to the Consortium THTR made up of HRB, Brown, Boveri \& Cie., and NUKEM. The construction site was selected by HKG to be on a power plant site of the utility Vereinigte Elektrizitäswerke Westfalen (VEW) near Schmehausen.

Construction began in 1971 with commercial operation expected in 1978. Due in large part to licensing difficulties, commercial operation has been delayed until 1981-1982.

\subsection{PLANT DATA}

The THTR is a dual-cycle plant for commercial electricity generation, i.e., a primary circuit for the generation of steam and a secondary cycle which converts steam energy into electricity. The primary circuit, consisting of a pebbie bed core and six parallel coolant loops, is housed in a massive prestressed concrete reactor vessel (PCRV). Each of the six parallel loops contain gas ducting, a steam generator, and a helium circulator. The high pressure steam generated is piped to a turbine generator and returned to the steam generators using the familiar Rankine cycle with five stages of feedwater heating. Waste heat from the THTR is removed via one natural draft dry cooling tower. The basic design data for THTR is summarized on Table 5-1. It should be pointed out that the PCRV is not 
TABLE 5-1

THTR BASIC DESIGN DATA

Characteristics of the overall plent

\begin{tabular}{|c|c|c|}
\hline Thermal core power & 750 & MW \\
\hline Net electrical power & 300 & MW \\
\hline \multicolumn{3}{|l|}{ Timary circuit data } \\
\hline Core diameter & 5.6 & $\mathbf{m}$ \\
\hline Core height & 6 & m \\
\hline Number of fuel element spheres & 75000 & \\
\hline Volume of pebble bed & 125 & $m^{3}$ \\
\hline Power density & 6 & $\mathrm{MW} / \mathrm{m}^{3}$ \\
\hline Helium flow rate & 295.5 & $\mathrm{kp} / \mathrm{s}$ \\
\hline Helium temperature outlet steam generator & 250 & ${ }^{\circ} \mathrm{C}$ \\
\hline Helium temperature inlet steam generator & 750 & ${ }^{\circ} \mathrm{C}$ \\
\hline Mean operating pressure of helium & 39. & bar \\
\hline Fuel element diameter & 6 & $\mathrm{~cm}$ \\
\hline Heavy metal content & $\begin{array}{l}0.96 \\
10.2 \\
\end{array}$ & $\begin{array}{l}g \cup 235 \\
\text { (93\% enriched) } \\
\mathrm{g} \text { Th } 232 \\
\end{array}$ \\
\hline Number of incore rods & 42 & \\
\hline Number of reflector rods & 36 & \\
\hline Number of coolant gas blowers & 6 & \\
\hline Number of steam generators & 6 & \\
\hline \multicolumn{3}{|c|}{ imensions of prestressed concrete pressure vessel } \\
\hline Inside diameter & 15.9 & m \\
\hline Inner height & 15.3 & $\mathbf{m}$ \\
\hline Wall thickness of cylinder & 4.45 & $\mathbf{m}$ \\
\hline Wall thickness of bottom slab & 5.1 & $\mathbf{m}$ \\
\hline Wall thickness of top slab & 5.1 & $\mathbf{m}$ \\
\hline Operating pressure & 39 & bar \\
\hline Test pressure & 46 & bar \\
\hline
\end{tabular}

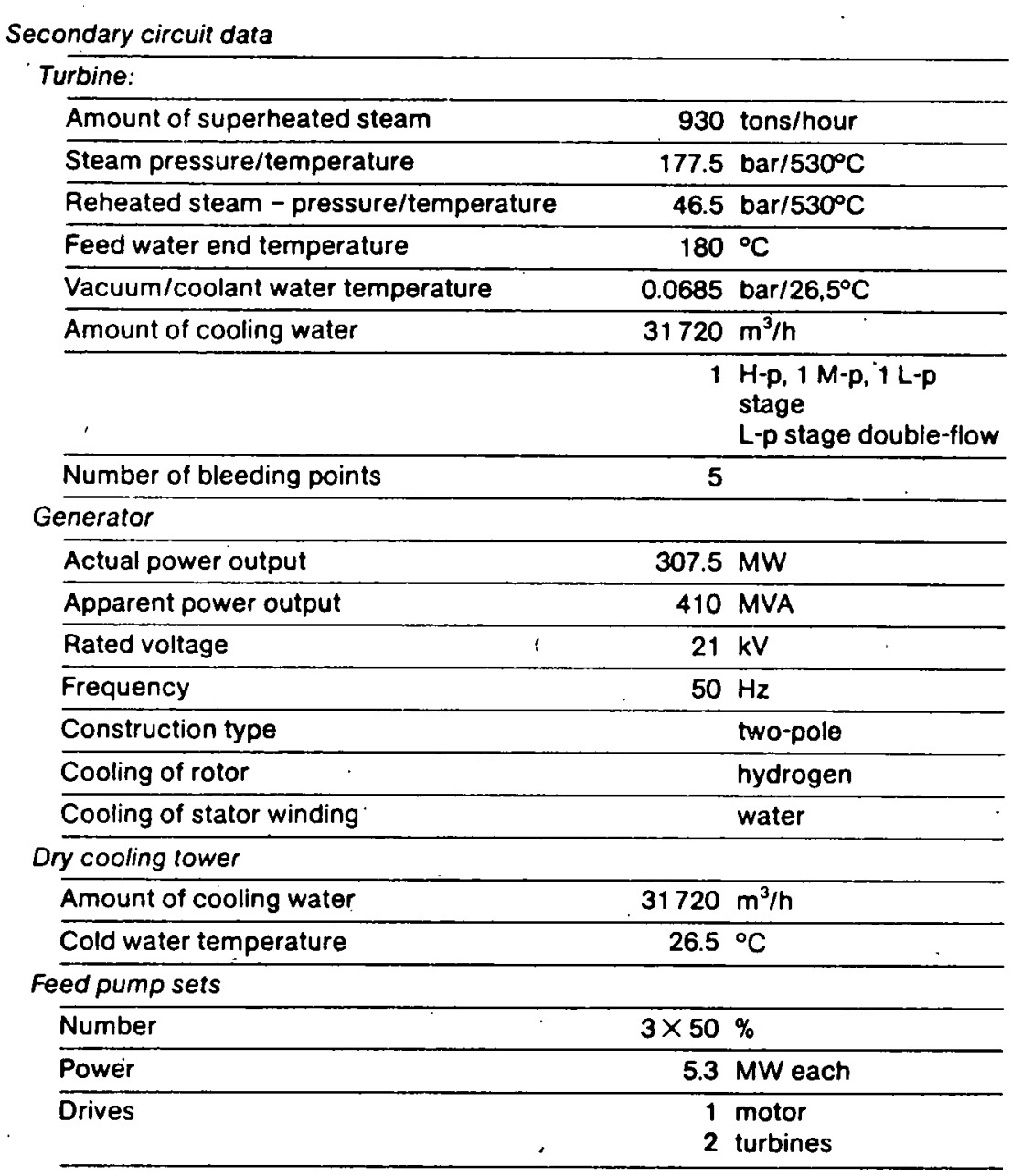


housed in an external concrete reactor building.

\subsubsection{PRESTRESSED CONCRETE REACTOR VESSEL (PCRV)}

The PCRV is a vertical cylinder containing the reactor core, steam generators, circulators, control rods, etc. The prestressing tendons compensate for all foreseeable internal pressures during the expected thirtyyear life. The steel liner fixed to the inner surface of the concrete ensures that the primary circuit is leaktight. The liner is insulated from primary temperatures on the inside and cooled on the outside by cooling piping between the liner and the concrete. Figure 5-1 provides horizontal and vertical views of the PCRV.

\subsubsection{PEBBLE BED CORE}

The pebble bed core consists of 675,000 fuel balls in the equilibrium core characterized by different degrees of burnups. The balls are inserted at the top of the bed and removed at the bottom by a fuel handling system described in the next section. The on-line refueling capability reduces the required excess reactivity and obviates the need for refuelling shutdowns. As a consequence, the capacity factor for the plant should be at least $80 \%$.

During the initial startup period, three types of pebbles are used: fuel bal1s, graphite balls, and absorber balls. As equilibrium is reached, the latter two types are replaced by fuel balls. The fuel balls consist of an inner matrix of coated fuel particles. These particles are mixed Uranium (93\% enriched) and Thorium Oxide, 400 micrometers in diameter, with three coatings of pyrolytic graphite. Each fuel element is made of NUKEM-A3 graphite and contains .96 grams of U-235 and 10.2 grams of Thorium.

Reactivity control is accomplished by the on-line refuelling and two sets of helium-cooled control rods. There are 36 electrical control rods which move in bore holes in the side reflectors. These rods are used for load following and are gravity inserted for quick shutdowns. The reflector rods are backed up by 42 helium-driven piston control rods that are inserted directly into the pebble bed. The in-core rods are used to bring the core to cold shutdown conditions, much in the same way as chemical 


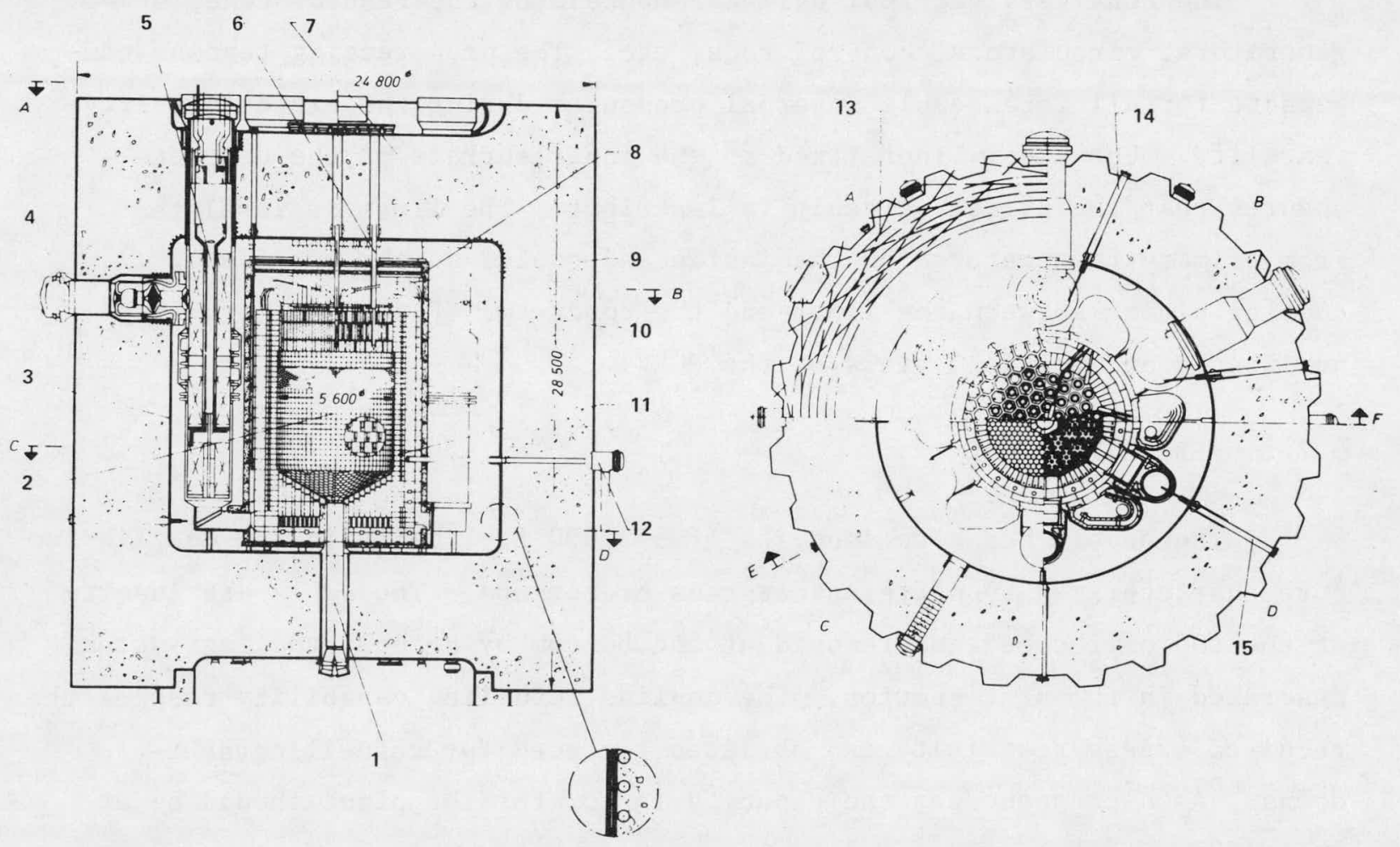

Section of the Prestressed Concrete Pressure Vessel

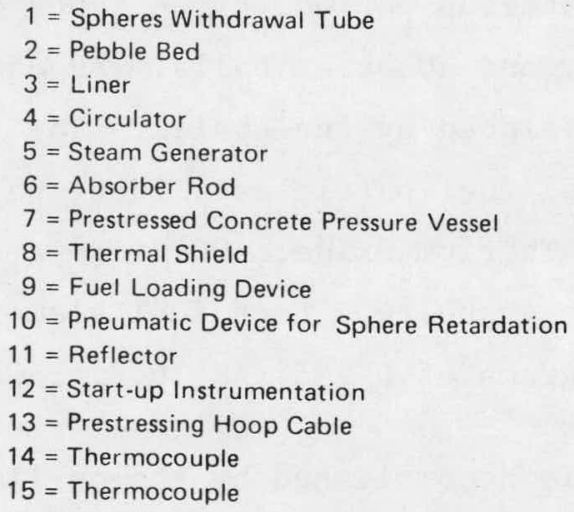

Figure 5-1. THTR Prestressed Concrete Reactor Vesse1 
shimming is used in pressurized water reactors. The control rods utilize canned $\mathrm{B}_{4} \mathrm{C}$ as the absorber material, and when an all-rods-in signal is received, ammonia $\left(\mathrm{NH}_{3}\right)$ is injected into the primary circuit to reduce friction forces for the in-core rods. Most accident sequences only require scramming of reflector rods, and the deep insertion scram of core rods should not be required.

The core is supported and surrounded by ceramic material such as the top, bottom, and side reflectors. Figures $5-2 \mathrm{a}$ and $5-2 \mathrm{~b}$ show the components of these graphite and carbon structures.

\subsubsection{FUEL HANDLING SYSTEM}

The refuelling of the THTR pebble bed is accomplished while the plant is on line. A pneumatic system injects the balls into the top of the PCRV where they drop onto the pebble bed. The system is designed to make the required daily fuel manipulations during one 8 -hour shift, thus allowing system maintenance during the other shifts. The fuel balls are recirculated to the core after being removed from the bottom if the burnup is not complete and if no damage has occurred. The burnup is measured by reactivity effect on a small test reactor located below the PCRV. The mechanical characteristics of the fuel handling system have been tested using a full-scale model at the HRB Laboratories in Jülich, Germany. Figure 5-3 is a schematic of the fuel handling system, and Figure $5-4$ shows the physical arrangement.

\subsubsection{REACTOR METALLIC INTERNALS}

Much of the material inside of the PCRV is metallic, such as the liner, thermal shields, hot gas duct insulation, etc. Figure 5-5 shows the arrangement of the PCRV metallic internals. Note that the circulator electric motors are outside the PCRV and shields are, therefore, needed to separate them from the hot helium. The major materials are listed below along with design temperatures. 


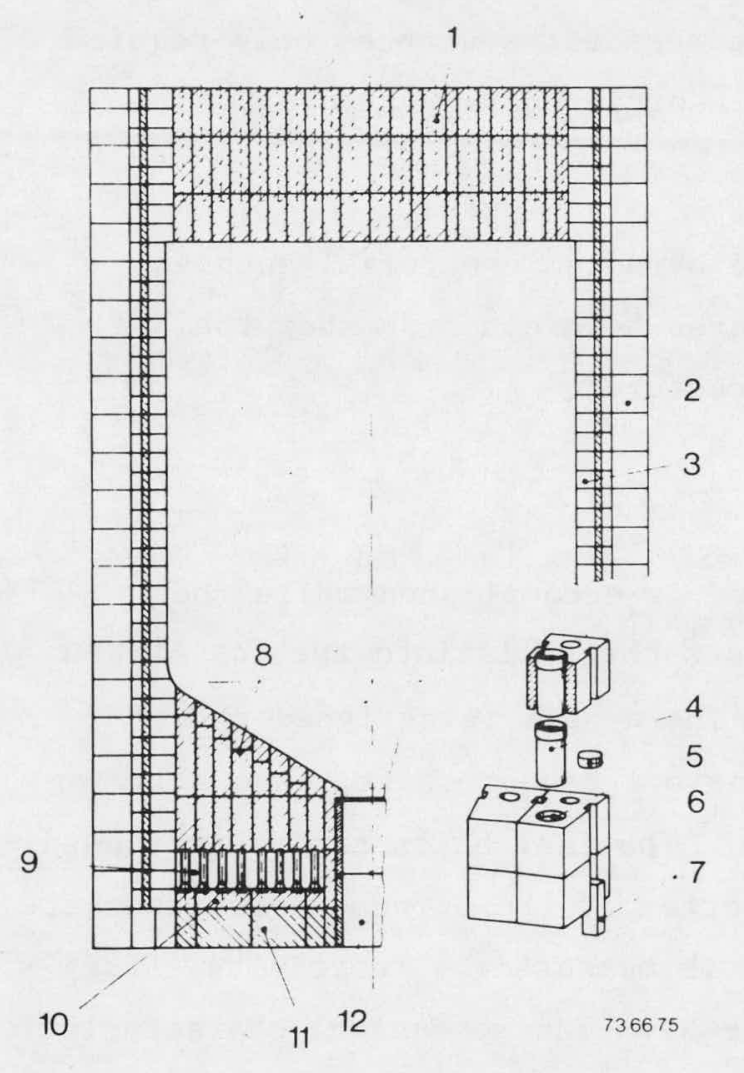

(a)

Ceramic Reactor Internals

$$
\begin{aligned}
1 & =\text { Top Reflector } \\
2 & =\text { Outer Side Reflector } \\
3 & =\text { Inner Side Reflector } \\
4 & =\text { Reflector Rod Sleeve } \\
5 & =\text { Dowel } \\
6 & =\text { Reflector Rod Bore Hole } \\
7 & =\text { Key } \\
8 & =\text { Bottom Reflector } \\
9 & =\text { Hot Gas Plenum } \\
10 & =\text { Graphite Layer } \\
11 & =\text { Carbon Layer } \\
12 & =\text { Spheres Withdrawal Tube }
\end{aligned}
$$

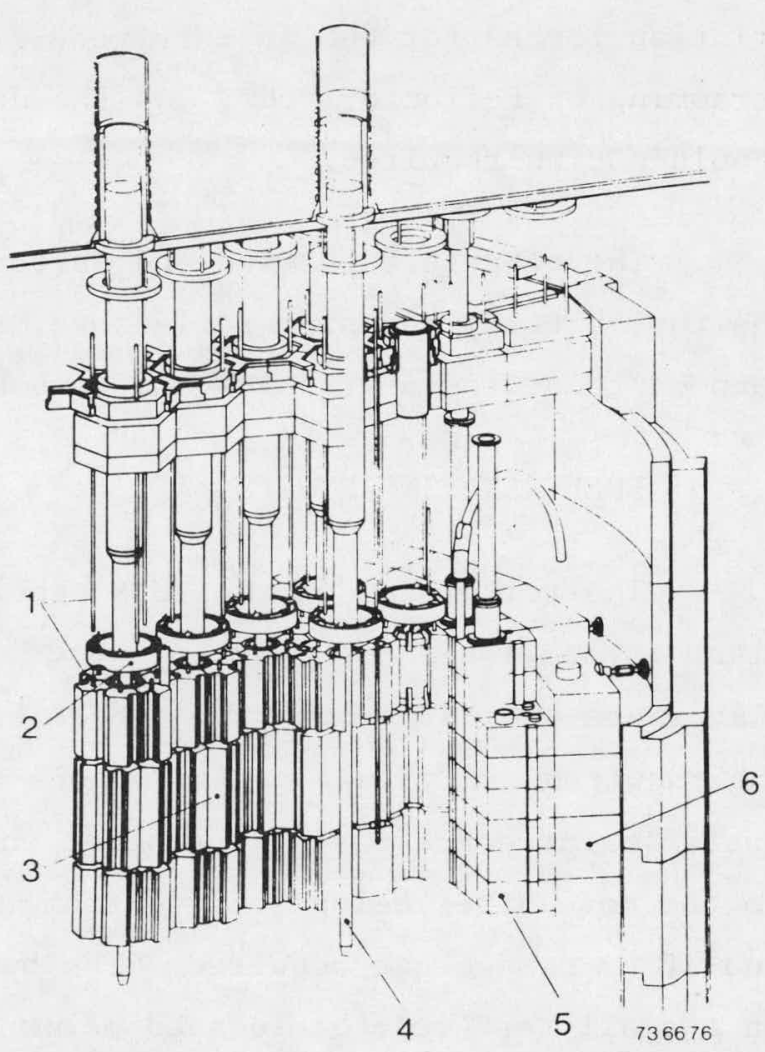

(b)

Top Reflector

$1=$ Anchoring Rod

2 = Support Ring

$3=$ Top Reflector

$4=$ In-core Rod

$5=$ Inner Side Reflector

$6=$ Outer Side Reflector

Figure 5-2. THTR Ceramic Reactor Internals 
1 Core

2 Prestressed concrete pressure vessel

3 Broken sphere separator

4 Broken sphere container

5 Lock

6 Fuel sphere loading assembly

7 Burn-up measuring reactor

8 Computer

9 Branching switch

10 Spent fuel element container

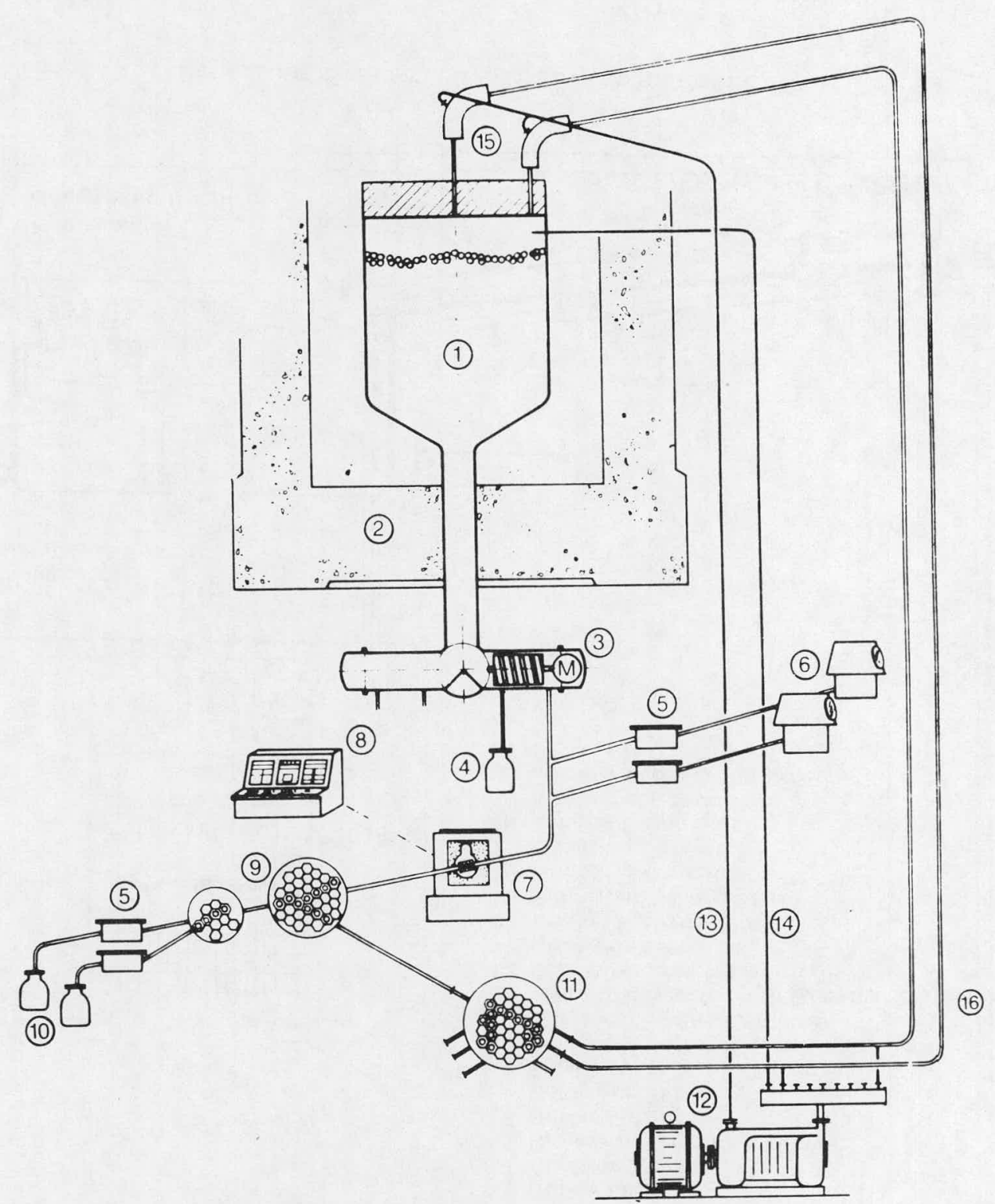

Figure 5-3. THTR Fuei Handling System Flow Schematic 


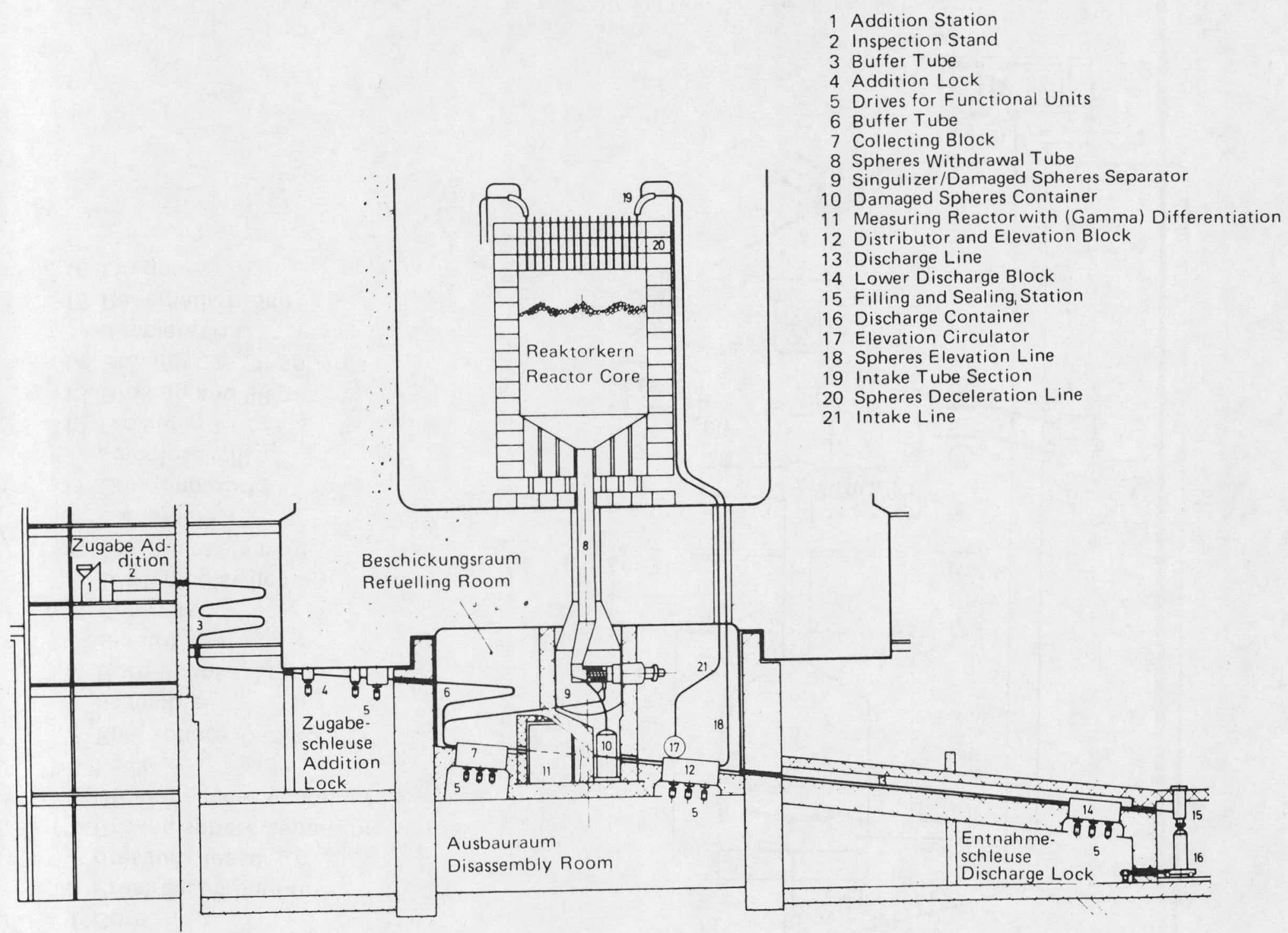

Figure 5-4. THTR Fuel Handling System Physical Arrangement 


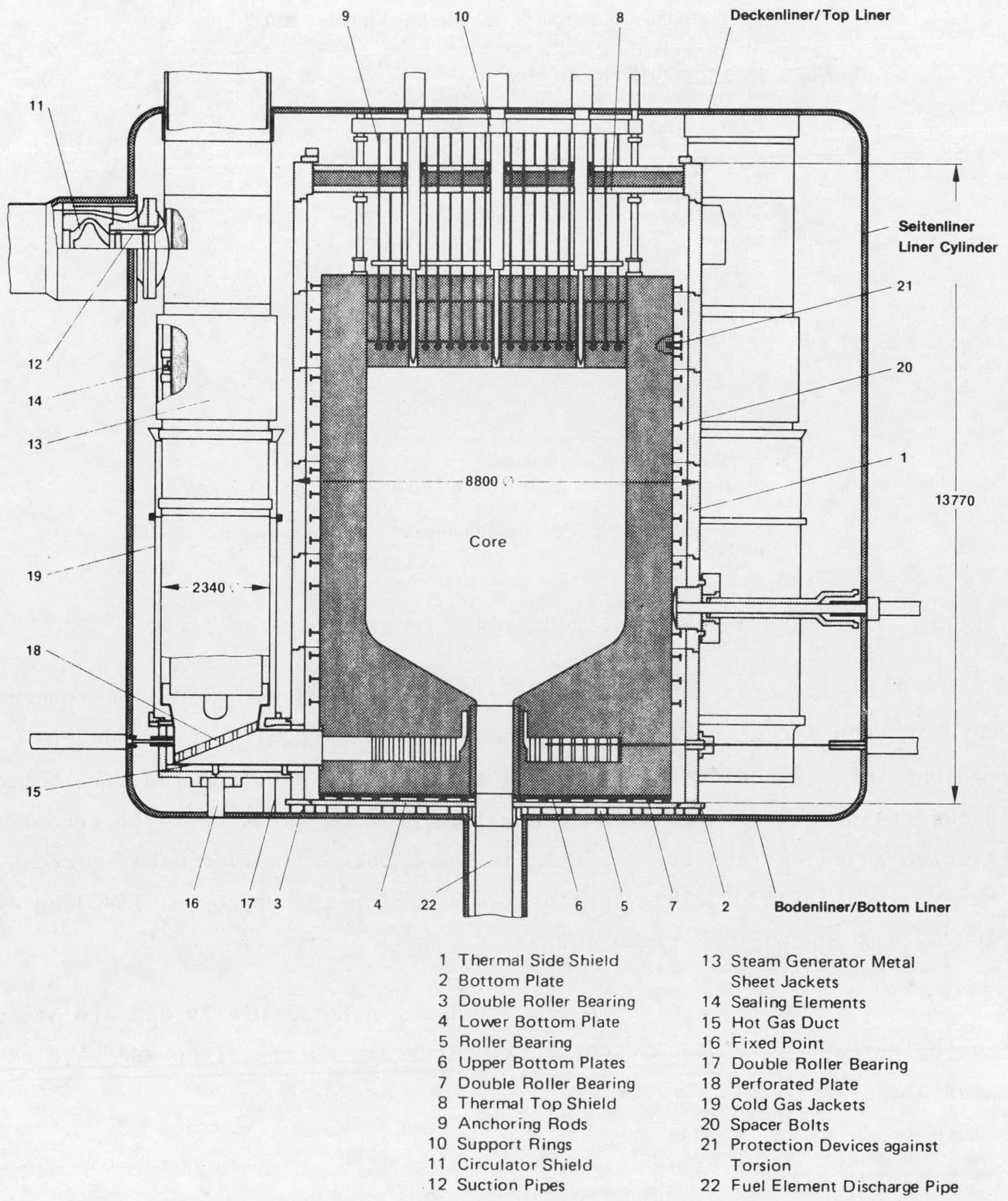

Figure 5-5. THTR Reactor Metallic Internals 


\section{Materials}

$\begin{array}{ll}\text { Hot gas duct insulation } & \begin{array}{l}\text { Mainly modified Incoloy } \\ 800\end{array} \\ \begin{array}{l}\text { Perforated plate } \\ \text { Steam generator metal sheet } \\ \text { jacket, hot gas duct, and top } \\ \text { reflector suspension } \\ \text { Cold gas jacket }\end{array} & 15 \text { Mo } 3 \\ \begin{array}{l}\text { Shields } \\ \text { Support bolts, roller bearing } \\ \text { and protection devices against } \\ \text { torsion }\end{array} & \mathrm{H} \mathrm{II} \\ \begin{array}{l}\text { Expansion joints } \\ \text { SKMU } 84 \text { (GG) }\end{array} \\ \begin{array}{l}\text { Design Temperatures } \\ \begin{array}{l}\text { Hot gas duct insulation and } \\ \text { perforated plate }\end{array}\end{array} \\ \begin{array}{l}\text { Lower part of steam generator } \\ \text { metal sheet jacket and hot gas } \\ \text { duct }\end{array}\end{array}$

All the other components are designed for a temperature of $\mathrm{t}=350^{\circ} \mathrm{C}$.

\subsubsection{STEAM GENERATORS AND CIRCULATORS}

The six steam generators are vertically mounted beside the reactor core and consist of helically wound heat exchangers with the secondary coolant (water) inside the tubes. The hot helium gas from the core bottom plows upward through the steam generator, passing first over the reheater section in co-current flow, then over the superheater in counter-current flow. Materials utilized include Incoloy 800 for high temperatures, 15 Mo 3 below $400^{\circ} \mathrm{C}$, and $10 \mathrm{CrMo} 910$ between $400-525^{\circ} \mathrm{C}$.

The six primary circulators are located horizontally and are attached to their respective steam generators. They are motor driven and have the general parameters listed below. 


$\begin{array}{lr}\text { per circulator: } \\ \text { medium delivered } & \text { Helium } \\ \text { capacity } & 46,25 \mathrm{~kg} / \mathrm{sec} \\ \text { intake pressure } & p_{\text {iabs }}=38,1 \mathrm{bar} \\ \text { intake temperature } & 250^{\circ} \mathrm{C} \\ \text { pressure increase } & 1,12 \mathrm{bar} \\ \text { speed } & \text { ca. } 5325 \mathrm{~min}^{-1} \\ \text { inner efficiency of cirulator } \eta \text { i } & 84,5^{\%} \\ \text { motor terminal power } & 2029 \mathrm{~kW} \\ \text { molor terminal power for design } & 2297 \mathrm{~kW} \\ \text { point at } 5600 \text { revolutions per minute } & 6000 \mathrm{~min}^{-1} \\ \text { maximum permissible operating speed } & >6800 \mathrm{~min}^{-1}\end{array}$

\subsection{THTR LICENSING STATUS}

Licensing of nuclear reactors in the Federal Republic of Germany is conducted in stages by issuing a series of partial licenses (Topical Report 8 discusses the conduct of German licensing in some detail). THTR has received eight of an anticipated total of twelve or thirteen partial licenses. The status is summarized below.

\begin{tabular}{|c|c|c|c|c|}
\hline $\begin{array}{l}\text { Partial } \\
\text { License Number }\end{array}$ & & & $\begin{array}{c}\text { Date } \\
\text { Received } \\
\end{array}$ & Topic \\
\hline 1 & & & May 1971 & $\begin{array}{l}\text { Overall Concept, and } \\
\text { Erection of the Reactor } \\
\text { Building, Service Building } \\
\text { and Operations Building }\end{array}$ \\
\hline 2 & & 18 & August 1972 & PCRV Erection \\
\hline 3 & & 8 & January 1973 & $\begin{array}{l}\text { Erection of the } \\
\text { Electrical Equip- } \\
\text { ment Building }\end{array}$ \\
\hline 4 & & 7 & September 1.973 & $\begin{array}{l}\text { Turbine Building, } \\
\text { Burnup Measurement } \\
\text { Facility, and the } \\
\text { Pumphouse }\end{array}$ \\
\hline 5 & & 19 & November 1974 & $\begin{array}{l}\text { Fuel Handling System, } \\
\text { Helium Storage \& Transport } \\
\text { System }\end{array}$ \\
\hline 6 & $\begin{array}{l}\text { 6A: } \\
\text { 6B: }\end{array}$ & $\begin{array}{r}4 \\
17\end{array}$ & $\begin{array}{ll}\text { March } & 1975 \\
\text { Apri1 } 1975\end{array}$ & $\begin{array}{l}\text { Helium Cleanup System } \\
\text { PCRV Internals }\end{array}$ \\
\hline 7 & & 22 & June 1976 & $\begin{array}{l}\text { Electric Equipment } \\
\text { Auxiliary Cooling Equipment }\end{array}$ \\
\hline 8 & & 16 & July 1976 & Condensate Polishing System \\
\hline
\end{tabular}


Since 1971 when THTR received its first partial license, there has been a multiplication in technical requirements imposed on nuclear plants. Topical Report 8 should be consulted for details on German safety criteria; however, it can be summarized here that the changes in technical criteria have had a negative impact on the construction schedule for THTR. There are three broad areas that have had the most impact,

(a) External Hazards - protection against aircraft impact, chemical explosion, severe seismic events, etc.,

(b) Internal Hazards - protection against guillotine rupture of ducts, pressure waves, thermal loads, jet forces, etc.,

(c) Single Failure Criteria - protection against single failures precluding safe shutdown and afterheat removal.

Looking first at the external hazards question, it is found that when THTR was designed, there were no requirements to protect safety-related equipment from air crashes or external explosions. The lack of an aircraft-hardened reactor building around the PCRV has made resolution of these new criteria particularly difficult. The plant was designed to withstand a seismic event consisting of a horizontal acceleration of $.1 \mathrm{~g}$. Now the plant must be analyzed for both horizontal and vertical accelerations of different magnitudes. The change did not result in design modifications, due to conservative engineering at the outset; however, significant expenditures of time and money were required to re-analyze all the systems and components. The concern for aircraft impact and chemical-explosions resulted in major design changes to a plant already partially constructed. Although the PCRV can withstand the revised loads, many components and systems could not. The control rod drives were found to be vulnerable to aircraft impact and an immense protective covering is, therefore, being erected over the top of the PCRV. New walls have to be constructed around certain components and in some cases components have to be relocated. A good example of a major relocation is the shifting of the huge feedwater storage tank from a position near the top of the plant into a special new building. The afterheat removal system also had to be rearranged in order to preclude external hazards knocking out both trains simultaneously. 
More severe single failure criteria forced numerous changes to system design and arrangement, as did the increased requirements for separation of redundant systems and components (e.g. cable raceways had to be moved and emergency feedwater piping had to be separated). The question of a seconclary redundant reactivity control system has also been raised. The Reactor Safety Commission (RSK) has not yet ruled upon this problem. Current FRG regulations specify $N$ minus two redundancy (i.e. one under repair followed by a single failure) for safety systems. As a result, $3 \mathrm{x}$ $100 \%$ or $4 \times 50 \%$ redundancy is used for new plants. The THTR afterheat removal system has acceptable $(4 \times 100 \%)$ active component redundancy (pumps and valves), but only $2 \times 100 \%$ capacity in passive components. In February 1977, the RSK ruled that the THTR design would be acceptable for this prototype plant, since the inherent safety (heat capacity) allows over three hours for corrective action should both ECCS systems be lost.

Another issue related to afterheat removal was the post-accident sequence. The original design for post-accident heat removal used bypass steam flow to the main condenser to $\operatorname{cool}$ and depressurize the primary circuit to below the shutoff head for the ECCS systems. The reviewing agencies postulated that the flow path to the condenser could be lost. The consequence of this view was that a new interim cooldown method had to be provided to drop the primary temperature/pressure to conditions acceptable to the ECCS. The method selected was to boil off the water in the steam generators to a special flash tank added to the ECCS system supplemented by new relief valves. A separate backup manual system is also being considered.

This modification to the post-accident cooldown scenario displays how a system alteration results in multiple impacts. The additions to the ECCS system resulted in design work, construction efforts, and new transients to analyze. These new transients yielded different dynamic stresses, loadings, temperatures, and flows than originally planned. The new conditions had to be imposed upon relevant systems and components and compared against design limits. Thus not only did the modifications cost time and money, but they also resulted in secondary effects with 
similar penalties. Such ripple effects were common due to the interactive nature of a nuclear plant, and added more delays to the construction schedule.

Significant licensing experience has thus been gained for pebble bed reactors as the result of the THTR proceedings in the licensing climate of Germany. The consequences of the new regulations on THTR have been major delays in the construction schedule and real cost escalation. It is clear that the fundamental concept is sound and that the delays are not a negative reflection on the safety of PBRs. The experience gained in: licensing THTR will form a good foundation on which to base safety and licensing efforts for future commercial-size pebble bed reactors. 
SECTION 6

REFERENCES

1. Beckurts, K.H., et al., "The Gas Cooled High Temperature Reactor: Perspectives, Problems, and Programs," JAEA-CN-36/94 (I.C.).

2. Mülder, H.W., Schöning, J., "The Development and Characteristics of the German High Temperature Reactor."

3. Bromkamp, K.H., Hantke, H.J., "Operating and Maintenance Experience with the AVR Experimental Power Station," IAEA-SM-127/20.

4. Ziermann, E.L., "Operating Experience with the AVR Experimental Power Station," IAEA-SM-200/39.

5. Nieder, R., and Ivens, G., "The Effect of Coolant Gas Impurities and Fast Neutron Dose on the Materials of the Primary Circuit of the AVR Reactor."

6. Ivens, G., "AVR-HTR Operating Experience," CONF-740501.

7. Knüfer, H., "Preliminary Operating Experiences with the AVR at an Average Hot-Gas Temperature of $950^{\circ} \mathrm{C}$," Nuclear Engineering \& Design, 34 (1975), pp. 73-83.

8. Nieder, R., et al., "Operational Experience with the AVR High Temperature Reactor at a Gas Outlet Temperature of $950^{\circ} \mathrm{C}$," Conference on Reactor Operating Experience, Chattanooga, Tennessee. TANSAO 26 (Supp1. 1) 1977, ISSN : 0003-018X.

9. Ivens, G., Gilli R., "The First Year of Operation at $950 \mathrm{C}$ in the AVR Power Station," IAEA-SH-200/38.

10. "Dragon, General Description," Nuclear Engineering, Juiy 1960.

11. Chapman, B.C., "Dragon Reactor Operating Experience,": DP-806, August 1972.

12. Chapman, B.C., "Operation and Maintenance Experience with the Dragon Reactor Experiment," DP-Report-884, May 1974.

13. Capp, P.D. and Simon, R.A. "Operational Experience with the Dragon Reactor Experiment of Relevance to Commercial Reactors," DP-Report-951, October 1975.

14. Graham, L.W., et a1., "HTR Fuel Development and Testing in the Dragon Project," CONF 74051, 1974.

15. Vaughan, R.D., "AGR Experience and its Relevance to Future Gas-Cooled Reactors." 
16. "Projektinformation Sheets Numbers 1-11," Konsortium THTR/Hochtemperatur Reaktorbau GmbH.

17. "HKG 300 MWe Nuclear Power Plant Uentrop with Thorium High Temperature Reactor in VEW Power Station Westfalen," Brown Boveri \& Cie, Hochtemperatur-Reaktorbau GmbH, October 1974. 